OAK RIDGE NATIONAL LABORATORY

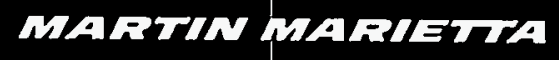

\section{Identification and Definition of Unbundled Electric Generation and Transmission Services}

\author{
Brendan Kirby \\ Eric Hirst \\ James Vancoevering
}

MANAGED BY

MARTIN MARIETTA ENERGY SYSTEMS, INC.

FOR THE UNITED STATES

DEPARTMENT OF ENERGY
DISTRIBUTION OF THIS DOCUMENT IS UNLIMTED

$$
\begin{aligned}
& \text { GH } \\
& \text { RECENED } \\
& \text { MAY } 19995 \\
& \text { OSTI }
\end{aligned}
$$


This report has been reproduced directly from the best available copy.

Available to DOE and DOE contractors from the Office of Scientific and Technical Information, P.O. Box 62, Oak Ridge, TN 37831; prices available from (615) 576-8401, FTS 626-8401.

Available to the public from the National Technical Information Service, U.S. Department of Commerce, 5285 Port Royal Rd., Springfield, VA 22161.

This report was prepared as an account of work sponsored by an agency of the United States Government. Neither the United States Government nor any agency thereof, nor any of their employees, makes any warranty, express or implied, or assumes any legal liability or responsibility for the accuracy, completeness, or usefulness of any information, apparatus, product, or process disclosed, or represents that its use would not infringe privately owned rights. Reference herein to any specific commercial product, process, or service by trade name, trademark, manufacturer, or otherwise, does not necessarily constitute or imply its endorsement, recommendation, or favoring by the United States Government or any agency thereof. The views and opinions of authors expressed herein do not necessarily state or reflect those of the United States Government or any agency thereof. 


\section{DISCLAIMER}

Portions of this document may be illegible in electronic image products. Images are produced from the best available original document. 
ENERGY DIVISION

\section{IDENTIFICATION AND DEFINITION OF UNBUNDLED ELECTRIC GENERATION AND TRANSMISSION SERVICES}

BRENDAN KIRBY, ERIC HIRST, and JAMES VANCOEVERING

March 1995

Sponsored by

Office of Energy Efficiency and Renewable Energy

U.S. Department of Energy

OAK RIDGE NATIONAL LABORATORY

Oak Ridge, Tennessee 37831

managed by

MARTIN MARIETTA ENERGY SYSTEMS, INC.

for the

U.S. DEPARTMENT OF ENERGY

under contract No. DE-AC05-84OR21400 


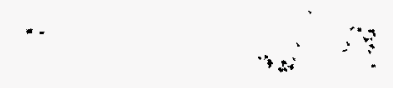




\section{CONTENTS}

\section{Page}

SUMMARY $\ldots \ldots \ldots \ldots \ldots \ldots \ldots \ldots \ldots \ldots \ldots \ldots \ldots \ldots \ldots \ldots \ldots$

LIST OF ACRONYMS $\ldots \ldots \ldots \ldots \ldots \ldots \ldots \ldots \ldots \ldots \ldots \ldots \ldots$

1. INTRODUCTION $\ldots \ldots \ldots \ldots \ldots \ldots \ldots \ldots \ldots \ldots \ldots \ldots \ldots \ldots \ldots \ldots \ldots \ldots$

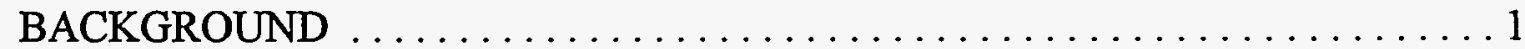

PURPOSE OF THIS PROJECT $\ldots \ldots \ldots \ldots \ldots \ldots \ldots \ldots \ldots \ldots \ldots$

2. BASIC SERVICES $\ldots \ldots \ldots \ldots \ldots \ldots \ldots \ldots \ldots \ldots \ldots \ldots \ldots \ldots \ldots \ldots$

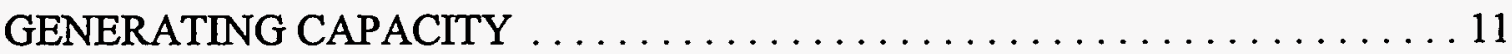

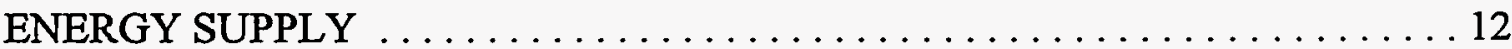

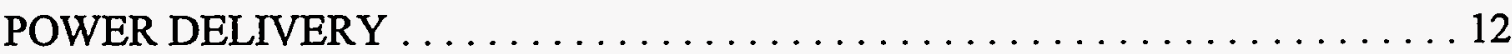

3. GENERATION-RELATED ANCILLARY SERVICES $\ldots \ldots \ldots \ldots \ldots \ldots \ldots \ldots \ldots$

ECONOMIC-MANAGEMENT SERVICES $\ldots \ldots \ldots \ldots \ldots \ldots \ldots \ldots \ldots \ldots$

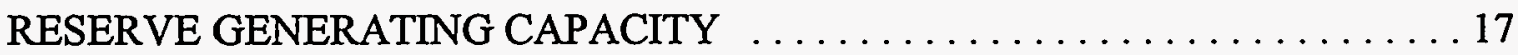

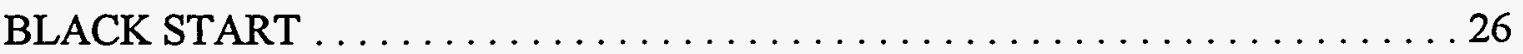

4. TRANSMISSION-RELATED ANCILLARY SERVICES . . . . . . . . . . . . 27

TRANSMISSION-SYSTEM MONITORING AND CONTROL . . . . . . . . 27

REAL-POWER-LOSS REPLACEMENT . . . . . . . . . . . . . . . . . . 29

REACTIVE-POWER MANAGEMENT AND VOLTAGE REGULATION . . . . 31

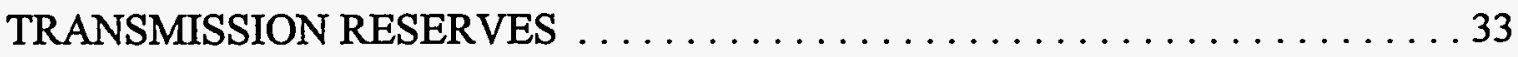

REPAIR AND MAINTENANCE OF NETWORK COMPONENTS $\ldots \ldots \ldots \ldots 33$

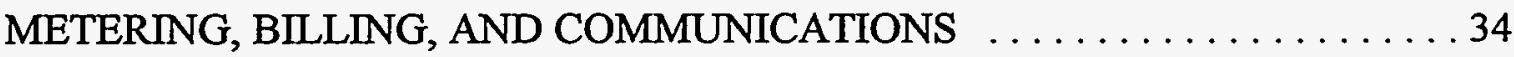

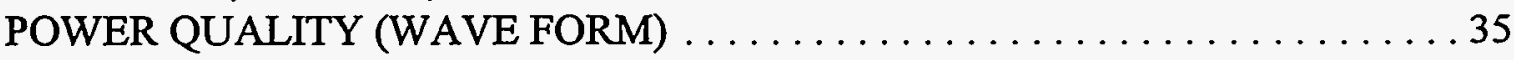

5. COMPARISON WITH OTHER DEFINITIONS $\ldots \ldots \ldots \ldots \ldots \ldots \ldots \ldots \ldots$

6. CONCLUSIONS $\ldots \ldots \ldots \ldots \ldots \ldots \ldots \ldots \ldots \ldots \ldots \ldots \ldots \ldots \ldots \ldots \ldots$

ACKNOWLEDGMENTS $\ldots \ldots \ldots \ldots \ldots \ldots \ldots \ldots \ldots \ldots \ldots \ldots \ldots \ldots \ldots$

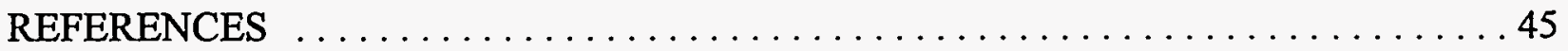




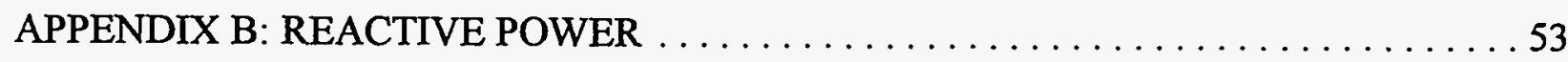




\section{SUMMARY}

State and federal regulators, private and public utilities, large and small customers, power brokers and marketers, and others are engaged in major debates about the future structure of the electric industry. Although the outcomes are far from certain, it seems clear that customers will have much greater choices about the electric services they purchase and from whom they buy these services.

This report examines the "ancillary" services that are today buried within the typical vertically integrated utility. These ancillary services support and make possible the provision of the basic services of generating capacity, energy supply, and power delivery. These ancillary services include:

- management of generating units;

- reserve generating capacity to follow variations in customer loads, to provide capacity and energy when generating units or transmission lines suddenly fail, to maintain electricsystem stability, and to provide local-area security;

- transmission-system monitoring and control;

- replacement of real power and energy losses;

- reactive-power management and voltage regulation;

- transmission reserves;

- repair and maintenance of the transmission network;

- metering, billing, and communications; and

- assurance of appropriate levels of power quality.

Figure S-1 illustrates schematically the integration and interactions within an electric system that require these ancillary services. The dotted line represents the boundary of a control area, within which the system (grid) operator regulates generation output to maintain the schedule of power flows with other systems and control frequency. The control area is connected to other control areas at five interfaces, labeled II through I5. Several generators, labeled G1 through G5, 
operate within the control area as do various loads, labeled L1 through L6. The generators and loads are connected to each other by a transmission grid, identified by the solid lines.

Changes at any interface, generator, or load affect-simultaneously - all other interfaces, generators, and loads. It is the system operator's responsibility, through the ancillary services discussed here, to ensure that these changes do not cause problems elsewhere on the network. (The system operator includes the people as well as the automatic control equipment that they manage.) So, for example, if generator G2 trips off the system, the operator must have sufficient reliability-spinning reserve available to quickly pick up the loss of output from G2. If a steel mill at L4 starts up, sufficient load-following-spinning reserve must be available to meet that load without a sustained sag in frequency. If one of the transmission lines between G3 and L1 becomes overloaded, the operator must have the flexibility to reconfigure the network to increase power over other lines (e.g., from G2 to L1), to back off the generation at G3 and increase it elsewhere, or both. These actions require transmission reserves and generation reserves, respectively. If a transmission component fails, the operator must have sufficient information and communications to identify the location and type of problem and then to dispatch repair crews to restore service.

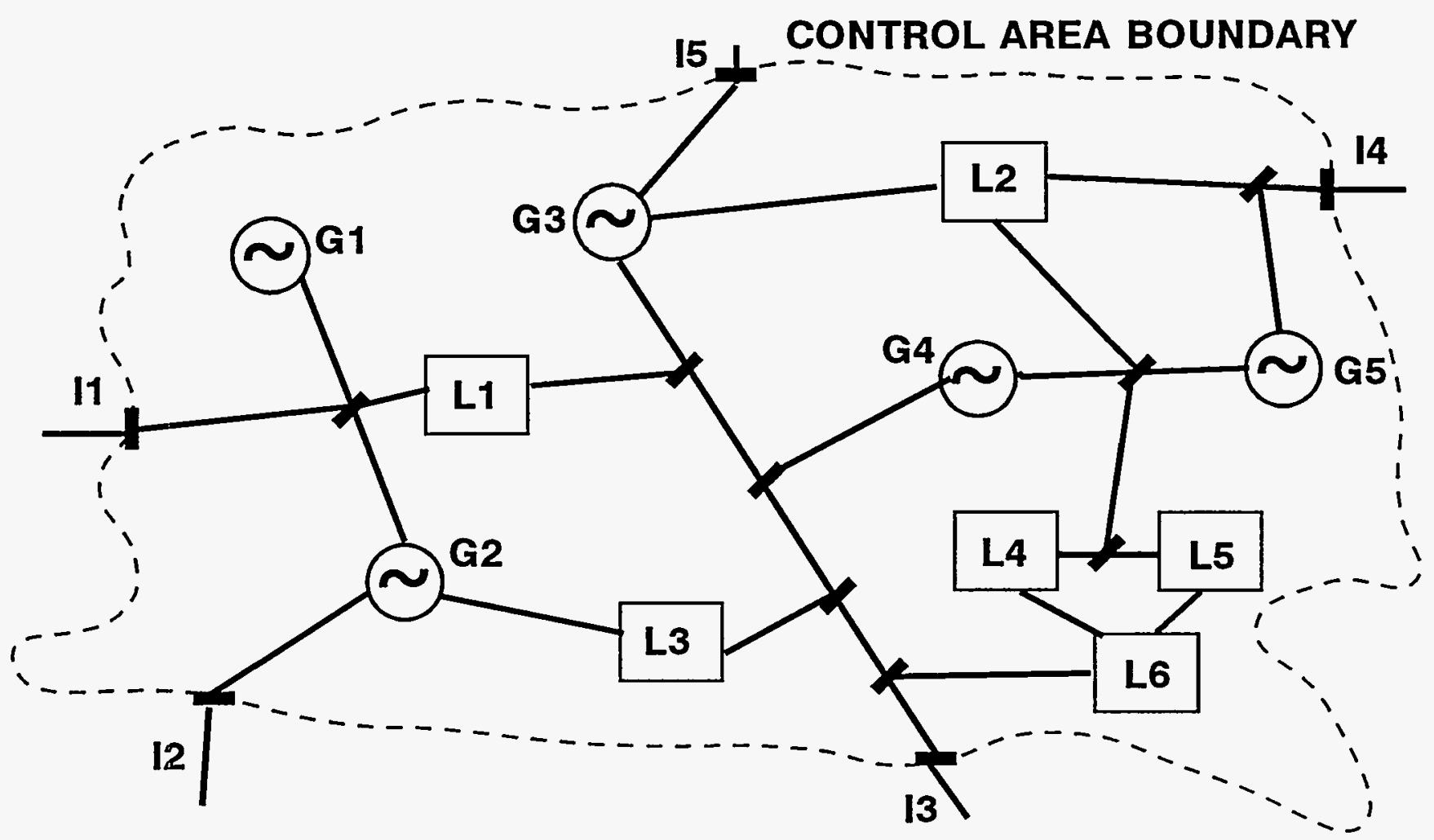

Fig. S-1. Schematic of an interconnected electric system showing generators (G), loads (L), interconnections with other systems (I), and transmission lines. 
For each of the basic and ancillary services discussed here, we seek to identify what the service is; the equipment and/or people used to provide the service; whether that service must be obtained from the system operator or can be obtained from a third party; whether that service is required or optional for the end user; whether customer use of the service can be controlled or metered by the system operator; whether there is currently a standard for this service; an indication of the cost of this service relative to that of the other services; and on what basis the service might be priced (e.g., $\$ / \mathrm{kW}$ peak demand).

Table S-1 shows our initial assessment of these services. For most customers (all those except fully interruptible customers), the following services are both mandatory and must be controlled by the system operator: reliability spinning reserves; unscheduled energy; time correction; stability enhancement; local-area security; black start; transmission monitoring and control; real-power-loss replacement; system reactive-power management and voltage regulation; transmission reserves; repair and maintenance of the transmission network; and metering, billing, and communications. Note that not all of these services must be supplied directly by the system operator; they could be provided by a third party, but they must remain under the control of the system operator.

Our focus in this report, the first output from a larger Oak Ridge National Laboratory project, is on identification and definition of these services. Later work in this project will examine more closely the costs and pricing options for each service. 
Table S-1. Preliminary assessment of ancillary services

\begin{tabular}{|c|c|c|}
\hline Service & $\begin{array}{l}\text { Required or } \\
\text { optional }\end{array}$ & $\begin{array}{l}\text { Must be obtained } \\
\text { from system } \\
\text { operator? }^{\mathrm{a}}\end{array}$ \\
\hline Generation capacity & Optional $^{b}$ & No \\
\hline Energy supply & Optional $^{\mathrm{b}}$ & No \\
\hline Power delivery & Optional & Yes \\
\hline Unit commitment & Optional & No \\
\hline Economic dispatch & Optional & Yes \\
\hline $\begin{array}{l}\text { Reserve generating capacity } \\
\text { - Load-following spinning reserve } \\
\text { - Reliability spinning reserve } \\
\text { - Unscheduled energy } \\
\text { - Supplemental operating reserve } \\
\text { - Time correction } \\
\text { - Stability enhancement } \\
\text { - Local-area security } \\
\text { - Nonoperating reserve }\end{array}$ & $\begin{array}{l}\text { Required } \\
\text { Required } \\
\text { Required } \\
\text { Optional } \\
\text { Required } \\
\text { Required } \\
\text { Required } \\
\text { Optional }\end{array}$ & $\begin{array}{l}\text { No } \\
\text { Yes } \\
\text { Yes } \\
\text { Yes }^{d} \\
\text { Yes } \\
\text { Yes } \\
\text { Yes } \\
\text { No }\end{array}$ \\
\hline Black start & Required & Yes \\
\hline Transmission monitoring and control & Required & Yes \\
\hline Real-power-loss replacement & Required & Yes \\
\hline $\begin{array}{l}\text { System reactive-power management and voltage } \\
\text { regulation }\end{array}$ & Required & Yes \\
\hline $\begin{array}{l}\text { Local reactive-power management and voltage } \\
\text { regulation }\end{array}$ & Required & No \\
\hline Transmission reserves & Required $^{c}$ & Yes \\
\hline Repair and maintenance of network & Required & Yes \\
\hline Metering, billing, and communications & Required & Yes \\
\hline Power quality & Optional & No \\
\hline \multicolumn{3}{|c|}{$\begin{array}{l}\text { a"Obtained from the system operator" means that the service must be under the control } \\
\text { of the system operator, who can either provide that service or contract with another party to } \\
\text { rovide the service. } \\
\text { bWhile generating capacity and energy supply are both optional, a customer will certainly } \\
\text { want at least one of these services. } \\
\text { "These services are optional only for fully interruptible customers. } \\
\text { dThese services could be provided by a generation supplier for particular customers. }\end{array}$} \\
\hline
\end{tabular}




\section{LIST OF ACRONYMS}

AC Alternating current

ACE Area control error

AGC Automatic generation control

DC Direct current

FERC Federal Energy Regulatory Commission

NEPOOL New England Power Pool

NERC North American Electric Reliability Council

ORNL Oak Ridge National Laboratory

SMES Superconducting magnetic energy storage

T\&D Transmission and distribution

VAR Volt-amperes reactive 


\section{INTRODUCTION}

\section{BACKGROUND}

Today's typical electric utility provides bundled services to its customers. Almost all residential customers think about and pay for electricity as a single, homogeneous product. The typical residential tariff includes only a customer charge $(\$ /$ month) and an energy charge $(\phi / \mathrm{kWh})$. Most commercial and industrial customers face demand charges $(\$ / \mathrm{kW}$-month) as well as energy and customer charges. Thus, they may view electricity as consisting of two elements, energy and capacity. Only the largest (generally, industrial) customers recognize some of the spatial and temporal complexities of providing electricity. These customers may have real-time pricing, in which the price of electricity varies from day to day and from hour to hour. But even in these cases, customers still generally pay only for energy and capacity.

In reality, electric-power systems provide many other services beyond the energy and capacity output from power plants. These services are provided by the utility's vertically integrated system of generating units; transmission lines, switchyards, substations, transformers, communication equipment, and control systems; distribution lines, substations, and transformers; and customer-service operations.

Electric utilities operate their systems to meet two primary and sometimes conflicting goals: least-cost provision of electricity and reliability of service to customers. Meeting both objectives simultaneously is difficult for three primary reasons:

- Storing electricity is difficult and expensive, so it usually must be generated at the same time that it is consumed.

- Because electricity moves through the grid at nearly the speed of light, many important events occur in less than a $60-\mathrm{Hz}$ cycle $(17 \mathrm{~ms})$; so decisions must be made and implemented quickly (frequently automatically).

- The present $\mathrm{AC}$ electric system, from generators to customers, is interconnected, so changes anywhere in the system affect all other points in the system.

To operate their electric systems economically and reliably in the face of these three factors, all utilities are part of a control area. According to the North American Electric Reliability Council (NERC), a control area is "a system which regulates its generation in order to maintain its interchange schedule with other systems and contributes its frequency bias obligation to the 
Interconnection" (NERC 1994). The purpose of control areas is to subdivide the system into units small enough to contain disturbances and to keep them from affecting interconnected system operations. The New England Power Pool (NEPOOL, which is a large control area) takes a more expansive view of the basic services that it provides: "regulating system frequency, maintaining system voltage, managing the flow of electricity (both scheduled and emergency) between NEPOOL and neighboring pools, managing NEPOOL members' capacity to meet system load and operating reserve, managing the NEPOOL members' transmission system, and coordinating daily transmission and generation outages" (NEPOOL 1995).

The system (or grid) operator typically has control over many generating units that he dispatches to ensure that generation and loads match, to ensure that actual interchanges with other control areas equal scheduled interchanges, and to maintain system reliability and stability ${ }^{*}$ in accordance with guidelines set forth in the NERC Operating Manual (Exhibit A). The NERC regions (covering the United States and portions of Canada and Mexico) have about 150 control areas.

The system operator, in balancing the competing goals of economics and reliability, provides services to customers beyond the supply of raw energy and capacity. These services, the subject of this report, include those provided by generating units and the transmission system. A partial listing of services provided primarily by generating units includes economic dispatch and spinning reserves. Services provided primarily by the transmission system include network monitoring and control, loss management, transmission reserves, and outage response.

Traditionally, customers, regulators, and even many utility employees could safely ignore these ancillary services. They did not need to be considered separately because they were provided by the same entity and paid for by all customers.

New technologies, low natural-gas prices, federal legislation, and federal and state utility regulations are restructuring the electricity industry. Today's vertically integrated utility with a retail monopoly franchise may be a very different organization in a few years. Industry restructuring might involve deintegration of today's utilities, much greater competition in wholesale electricity markets, and perhaps greater competition in retail electricity markets.

"Reliability refers to the system's ability to deliver uninterrupted (continuous) service to customers. Reliability depends on the performance of and redundancy in the generation, transmission, and distribution systems. Perfect reliability is too expensive to achieve. Stability refers to the system's ability to maintain a synchronized frequency throughout the system. A system is unstable if perturbations from synchronization grow, forcing generators and transmission components to disconnect from the system. A stable system is one in which such perturbations die out quickly. 
Exhibit 1. The North American Electric Reliability Council Operating Manual

NERC was established in 1968 as a response to a blackout in 1965 that left almost 30 million people in the northeastern United States and Ontario, Canada without electricity. NERC includes nine reliability councils that cover all of the contiguous United States and parts of Canada and Mexico. These reliability councils establish and maintain standards for the safe and reliable operation of electric-power systems.

The NERCOperating Manual (NERC 1994) defines many of the procedures that electric utilities use to maintain system reliability and stability: The Manual includes several operating guides that cover the following topics:

- Systems control generation, voltage control, time and frequency control, interchange scheduling, control performance criteria, inadvertent-interchänge management, control suryeys, and control-equipment requirements.

- System security: real power supply; reactive power supply; transmission operation; relay coordination; monitoring interconnection parameters; information exchanges on system conditions; disturbances, and sabotage; and maintenance coordination.

- Emergency operations insufficient generation capacity, transmission overloads or voltage control, load shedding, system restoration, emergency information exchange, special system or control-area action, and control-center backup.

- Operating personnel: responsíbility and authority, selection, training, and responsibility to other operating groups.

- Operations planning: normat operations, emergency conditions, long-term deficiencies, ,load shedding, and system restoration.

- Telecommunications: facilities, procedures, and loss of communications.

The Manual also includes training documents on control performance criteria and inadvertent-interchange accounting, as well as information on electric-system restoration, backup control centers, and the system operator's perspective on demand-side-management programs.

The Energy Policy Act of 1992 and subsequent decisions by the Federal Energy Regulatory Commission [see, for example, FERC's (1994a) pricing-policy statement] require utilities to provide open access to their transmission systems. FERC now requires utilities to 
provide transmission services to other parties that are "comparable" to those provided to itself. The Energy Policy Act created a new class of power providers, called exempt wholesale generators. These generators, other independent power producers, brokers, and marketers are now free to buy and sell electricity in wholesale markets. Because of these changes, utilities may want to (or be required to) unbundle services that previously were provided as a package. In addition, the utility may not be the only entity that can supply some of these services; so customers might choose to obtain some services from other parties or provide some themselves.

Unbundling services is likely to benefit both electricity consumers and suppliers. Consumers will benefit because they will be able to pick and choose those services-and only those services-that they need, want, and are willing to pay for. Suppliers will benefit because they will be able to decide on the services to offer on the basis of their costs and what consumers are willing to pay for. Thus, unbundling will promote economic efficiency in the electric industry.

Regardless of whether wholesale competition focuses on the use of power pools or bilateral contracts, two facts remain true. First, the dispatch of generating units, storage, and controllable load must be coordinated to ensure that, moment to moment, loads and resources balance and that transmission constraints are recognized. Second, the power must flow through an interconnected transmission network from generators to end users.

Discussions of increased competition in electricity markets have paid little attention to the myriad of services provided by the centralized dispatch of power plants and operation of the transmission grid." A recent study noted that, "Too many of the current discussions of industry restructuring pass over this complexity with a cursory reference to the control function or the need to maintain operational reliability" (Cullen et al. 1994).

Some of the basic functions of the electric system are well defined, but many of the ancillary functions are more elusive. A primary goal of those interested in restructuring the electricity industry to increase competition should be to identify clearly the different functions that are today buried within the vertically integrated utility and bundled into one price. Ideally, one would like to identify a set of services provided by electric generating units and the transmission system that is (1) exhaustive (covers all the services provided) and (2) mutually exclusive (no overlap among identified services).

Achieving this ideal of offering unbundled services at appropriate prices will be difficult because of utility accounting practices (Sammut 1994). Table 1 shows the allocation of utility revenues using the FERC accounting formats. These categories do not include any specific cost

${ }^{*}$ See, as examples, comments filed by various parties with the California Public Utilities Commission (1994) in response to its April 1994 order on industry restructuring and competition as well as the statements of various parties before the U.S. House of Representatives (1994). Even Hogan (1993), a key architect of industry restructuring, has said little about ancillary services. 
assignments for ancillary services. For example, FERC Form-1 includes the following categories under transmission operation expenses: operation supervision and engineering, load dispatching, station expenses, overhead-lines expenses, underground-lines expenses, transmission of electricity by others, miscellaneous transmission expenses, and rents (FERC 1992). None of these categories relates directly to the ancillary services discussed here. Figure 1 illustrates the discrepancy between these accounting categories and actual utility operations.

Table 1. Allocation of 1992 revenues for major U.S. investor-owned electric utilities

\begin{tabular}{lcc}
\hline Operations and maintenance & $\begin{array}{c}\text { \% of total } \\
\text { revenue }\end{array}$ & $\begin{array}{c}\text { \% of total, with fixed costs } \\
\text { allocated to key functions }^{\mathrm{a}}\end{array}$ \\
\hline Generation & $(58)$ & 67 \\
Transmission & 44 & 6 \\
Distribution & 1 & 14 \\
Customer service & 3 & 4 \\
Administrative and general & 3 & 10 \\
& 7 & \\
Fixed costs & & \\
Depreciation and amortization & $(42)$ & \\
Income taxes & 10 & \\
Other taxes & 4 & \\
Interest payments & 10 & \\
Net income & 9 & \\
\hline
\end{tabular}

Source: Energy Information Administration (1993).

${ }^{a}$ Generation accounted, in 1992 , for $54 \%$ of net utility plant, transmission for $11 \%$, distribution for $25 \%$, and customer service and administrative and general for $10 \%$. The numbers do not sum to $100 \%$ because of rounding errors.

In addition, cleanly unbundling these services will be difficult because some services draw on multiple pieces of equipment and because individual pieces of equipment often contribute to more than one service (Fig. 2). For example, a generating unit provides real power and energy (the $\mathrm{kW}$ and $\mathrm{kWh}$ outputs that are the primary purpose of the machine). In addition, generators produce reactive power, which contributes to operation of the transmission system. The mass of generators plus the ability to control voltage and frequency help maintain a stable electric system. Transmission lines provide the transportation link between generators and consumers. In addition, these lines absorb reactive and real power, thereby consuming services. 


\section{ACCOUNTING}
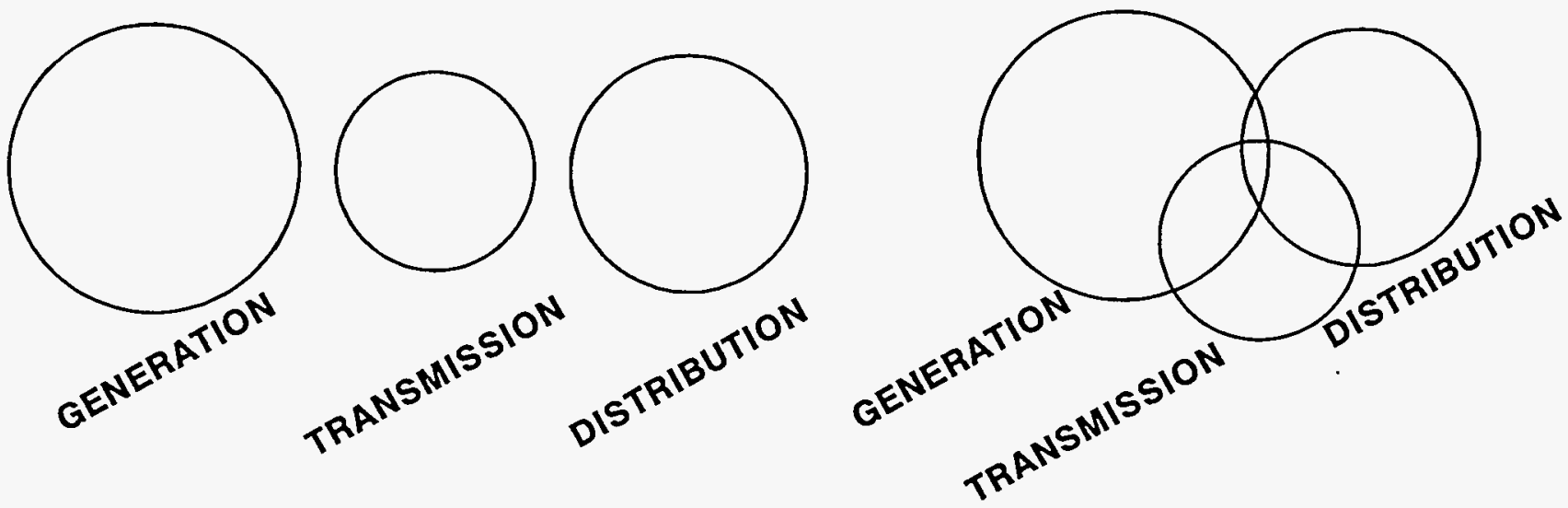

Fig. 1. Differences in accounting treatment and actual operation of the integrated electric-system equipment.

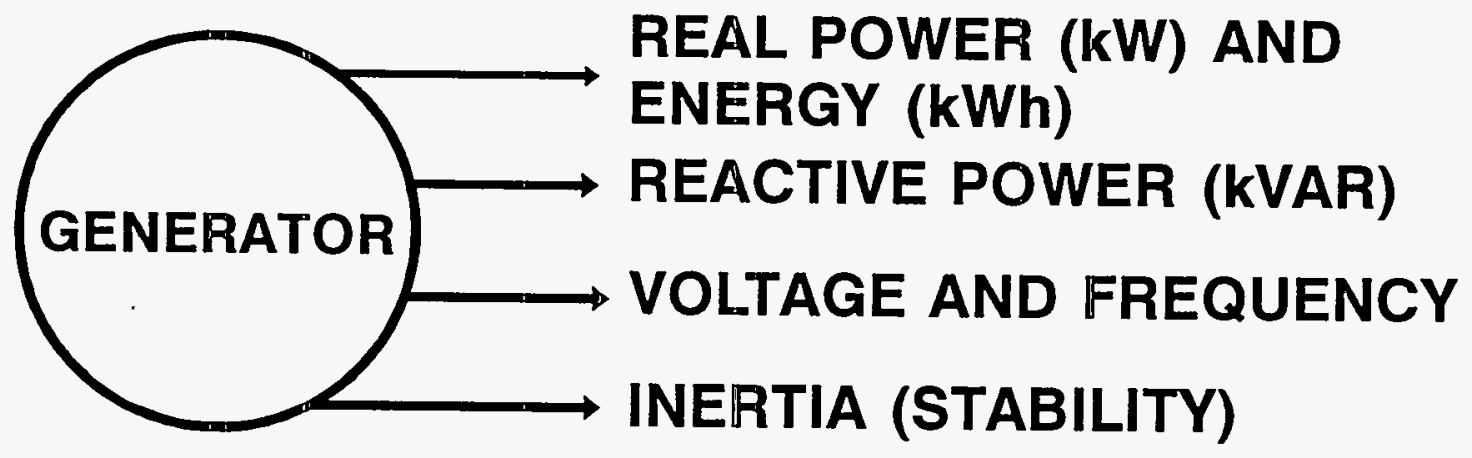

Fig. 2. Example of joint production from one type of equipment. A generating unit provides reactive power, voltage support, frequency control, and inertia, as well as the basic outputs of real power and energy.

The electrical system is highly integrated, so actions in one location can affect service at many other locations. A December 14, 1994, outage of the 500-kV Pacific Intertie illustrates this integration uncomfortably well. Although the outage was short and restoration operations went well, it affected 1.5 million people in 11 western states and British Columbia (Electric Light \& Power 1995). Two months after the outage, the Western Systems Coordinating Council was still investigating the cause of the disturbance.

Finally, information asymmetries may complicate analysis of these ancillary services (Kahn 1995). Utilities, because they currently control and operate electrical systems, have more 
information on the costs of some of these services than do customers, independent power producers, or power brokers. Because utilities are competing with these other parties, they have an incentive to shift costs to them. This potential conflict of interest and information asymmetry complicate the task for regulators (as well as for researchers). To the extent that some of the ancillary services discussed here can be provided competitively (e.g., by nonutility entities), the problem is greatly reduced. However, regulators will have to pay close attention to those services that can be provided only by the system operator.

\section{PURPOSE OF THIS PROJECT}

This report, the first output from a larger Oak Ridge National Laboratory (ORNL) project on unbundling generation and transmission services, examines the various services that are provided by generators, electric-power control centers, and transmission networks. (We do not deal with distribution-system services in this report.) Identifying, quantifying, costing, and pricing these services is essential to the efficient operation of a competitive electricity market. Absent information on what these services are, their costs, and alternative pricing strategies, customers cannot make the kinds of informed choices that are the foundation of a competitive market. Similarly, providers, without this information, cannot decide what services to offer and what prices to charge.

This report identifies and defines the various functions provided by centralized dispatch and transmission services. Later activities in this project will include case studies of several utility control centers and power pools. We will simulate power flóws across various transmission configurations for different amounts and locations of generation and demand to quantify the services identified in earlier tasks. Finally, we will determine the extent to which these generation and transmission services can be unbundled and separately costed, whether and how they might be separately priced, and whether they can be provided by third parties.

This report is aimed primarily at senior staff and executives at electric utilities, state and federal regulatory commissions, environmental groups, industrial customers, and power marketers and brokers. Our semitechnical approach suggests that electrical engineers and system operators may already know much of what we present here.

For each of these basic and ancillary services we seek to identify:

- What the service is

The equipment and/or people used to provide the service

Whether that service must be obtained from the system operator (i.e., must be under the operator's control) or can be obtained from a third-party provider 
- Whether that service is required or optional for the end user

- Whether alternative ways exist to provide the service

- Whether customer use of the service can be controlled or metered by the system operator

- Whether a standard for this service exists

- A rough indication of its cost, relative to that of the other services identified

- On what basis the service might be priced (e.g., $\$ / \mathrm{kW}$ peak demand)

Determining whether a service is required depends on the consequences to the system if the customer does not use the service. A customer might want to do without the economicdispatch service and instead always obtain power from a specific generating unit. This will not harm the system, although it may result in higher costs (and possibly lower reliability) for the customer.

Determining whether a service must be obtained from the system operator depends on the information and control required to provide the service. If there is sufficient information available at the customer's location, then it is possible for the customer to provide the service itself or to contract with a third party for the service. If the information and control ability is available only to the system operator, then the service must be obtained from the system operator.

For example, because a customer can meter its own load, it can conceivably provide for load-following spinning reserve itself by directly controlling its load to eliminate fluctuations, by installing generation to compensate for the fluctuations, or by contracting with someone else to provide generation that compensates for fluctuations. It must obtain reliability spinning reserves from the system operator, however, because only the system operator knows when the area generation and load are out of balance because of the failure of a generator. This is true even if the customer is providing generation to the system that is dedicated to reliability spinning reserve. It is the system operator and his automatic equipment that tell the reliability spinning reserve when to respond.

Because of the complications associated with pricing transmission services [see, as examples, Hogan (1992) and Oren et al. (1994)], we do not suggest specific pricing formulas or mechanisms in this report. Also, while the primary purpose of this report is to identify the ancillary services, for completeness we describe the basic services as well.

We take no position in this report on the pros and cons of the debate in California over the structure of wholesale electricity markets. Specifically, we do not favor either the Poolco 
proposals advanced by Southern California Edison and San Diego Gas \& Electric or the bilateralcontracts approach advanced by Pacific Gas and Electric and Enron. Similarly, we take no position concerning the pros and cons of retail wheeling.

However, we believe that the work presented here (and to be developed throughout the course of this project) will be valuable to the participants in discussions about the future structure and operation of the electricity industry. As an example, consider alternative estimates of the costs of transmission services. The embedded cost of transmission averaged over all large investorowned utilities is $0.44 \phi / \mathrm{kWh}$ (Energy Information Administration 1993). On the other hand, Detroit Edison's retail-wheeling tariff proposes a charge of about $2.0 \% / \mathrm{kWh}$ for transmission and ancillary services (Musial 1994). The utility's proposal includes charges for administrative services; transmission-system reservation; generation support; substations; power-system voltage control; system control and load dispatch; capacity and energy losses; spinning reserve; supplemental reserve; reactive support; standby reservation; daily backup demand; backup energy; unauthorized demand and energy uses; plus customer-specific charges for metering, special services, redispatch, and economic priority. These two estimates $(0.4 \mathrm{vs} 2.0 \% / \mathrm{kWh})$ differ dramatically in part because they represent different services.

Unbundling may lead to higher prices for the same package of services that was previously provided in a bundled fashion. Two factors drive this judgment. First, unbundling increases transaction costs. More variables need to be measured, costed, and priced. Second, unbundling may lead to a loss in economies of scope. Offsetting these cost increases, however, is the possibility that greater choices will allow customers to pick and choose exactly those electrical services they want and need, no more and no less. Customers will have an economic incentive to minimize the use of services that they either do not need, that they can provide for themselves, or that they can obtain from another supplier at a lower cost. Similarly, competition among suppliers for those services that need not be provided by the system operator will likely lower their costs. The overall economic efficiency of the electric system might therefore improve.

We use the terms ancillary services, unbundled services, and services provided by the system operator or control area somewhat loosely in this report. Ancillary services are auxiliary or supplemental to other, basic services. In the present context, ancillary services are those that support the basic services of generating capacity and energy and power delivery. Unbundled services are those that have been taken out of a package that would otherwise aggregate several services into one. In that sense, unbundled is a more general term than is ancillary. Services provided by the system operator, as discussed throughout this report, might include some or all of the ancillary services. Thus, these three terms overlap and are likely to shift in meaning as electric-industry competition and markets evolve. Also, we include as services functions performed by the system operator that customers may not see directly, such as stability enhancement. These functions may be visible to other suppliers or may be integral to operation of the electric-power system. 
Chapter 2 describes the basic energy and capacity services provided by generating units and the transmission network. Chapter 3 describes the ancillary services provided primarily by the generating units, and Chapter 4 discusses those services provided primarily by the transmission system. Although we separate services into generation and transmission in this report, the split is artificial; many services require both generation and transmission equipment. Chapter 5 compares the list of services developed here with those developed by other utilities. Chapter 6 summarizes the status of the various ancillary services defined here and offers conclusions. 


\section{BASIC SERVICES}

The electric system provides customers two basic services, capacity (measured in MW) and energy (measured in MWh). The distinction between capacity and energy might diminish in the future, with today's separate demand and energy charges being replaced by energy charges that vary from hour to hour. Nevertheless, delivering electric services to customers requires both generating units and the transmission and distribution system.

\section{GENERATING CAPACITY}

Capacity refers to the amount of service (i.e., the ability to deliver electric energy) that a system or system component is capable of delivering. The most important and most expensive component that provides capacity is a generating unit. These facilities stand ready to provide electricity whenever customers want it.

While the service has historically been provided by the vertically integrated utility, it can be provided by any entity with generating capacity connected to the grid as long as there is sufficient transmission capacity to move the generation output to the customer.

Capacity margin is the amount of generating capacity available to provide for scheduled maintenance, emergency outages, system operating requirements, and unforeseen electricity demand. Utilities typically maintain a margin of 15 to $20 \%$ of peak demand. Only an amount of generation equal to the peak load is required for this basic generating capacity service, however. We discuss generating reserves in Chapter 3 and transmission reserves in Chapter 4 .

Nonresidential customers are often billed for capacity on the basis of their highest power use (typically based on the customer's maximum hourly demand) in a month. Many variations exist, such as using the highest monthly demand for the year, measuring demand only during onpeak hours, or adjusting for the coincidence of a customer's demand with the system peak.

Most customers will want this service, but it is not strictly required. A customer could avoid using this service by consuming electricity only when the utility had excess generating capacity available. The customer would place its load under the control of the system operator to ensure that the load was fully dispatchable and never placed a capacity burden on the utility. In other words, this customer would contract only for nonfirm (or interruptible) energy. More realistically, a customer might place part of its load under the system operator's control.

The cost of capacity is primarily the capital cost of the generating units used to meet demand at the time of system peak. The price customers pay for capacity is generally based on 
the utility's cost of meeting system peaks, usually expressed in $\$ / \mathrm{kW}$, where the demand reflects either the customer's maximum demand or the customer's demand at the time of system peak. A capacity charge thus reflects a "reservation" of the supplier's generating units.

\section{ENERGY SUPPLY}

Energy is the basic output of the generating units that customers use to provide light, heat, and mechanical power at their facilities. Like capacity, this service has historically been provided by the vertically integrated utility. But it is increasingly being provided by others with generating capacity connected to the grid. Most customers will want this service, although it is not strictly required. A customer might need generating capacity but no energy supply to back up reliable local generation.

The accounting assignment of costs to energy and capacity is detailed and intricate, primarily because the same equipment provides both services. The cost of energy always includes the variable cost of the generating plants. For most plants, these costs are dominated by fuel costs but also include the labor and maintenance costs that vary with unit use. Some portion of the capital cost of power plants is also assigned to energy costs, primarily to reflect the higher capital cost of baseload power plants relative to peaking units (e.g., $\$ 1500 / \mathrm{kW}$ vs $\$ 500 / \mathrm{kW}$ ). The price for nonfirm energy is usually somewhat higher than the variable cost but might not include the full contribution to the capital cost that a standard energy rate might include. Utilities charge customers for their energy consumption on a $\phi / \mathrm{kWh}$ basis.

\section{POWER DELIVERY}

The basic transmission service is the capacity to move power and energy from one place to another. The equipment used to perform this function includes transmission lines; substations (including switches, circuit breakers, transformers, and other equipment); communications, metering, and relaying equipment; and the control center from which the system is monitored and operated.

Utilities design their transmission systems as networks rather than as a set point-topoint connections. This design allows utilities to coordinate dispatch of multiple generators and loads and to reduce reliance on any single transmission component. Coordination reduces costs and increases generation reliability by spreading the reserve requirements (as discussed in Chapter 3). This design also allows utilities to take advantage of the temporal diversity among the peak demands of multiple customers. Customers are generally charged for transmission capacity based upon their peak-demand requirements (in terms of $\$ / \mathrm{kW}$-month). Alternatively, the transmission capacity charge could be based on the customer's demand at the time of system peak to reflect the coincidence of customer and system demands. 


\section{GENERATION-RELATED ANCILLARY SERVICES}

\section{ECONOMIC-MANAGEMENT SERVICES}

Table 2 lists a range of economic-management services that the system operator could provide to generators and customers. Within this category, only unit dispatch to instantaneously and continuously match generation and load and automatic protection of the grid are required services that can be provided only by the system operator. The other services could be performed by another party. These other services include long-term planning (1) to meet growing customer demands with new resources, (2) to provide fuels for generating units, and (3) to expand the transmission system to meet reliability requirements and to increase capacity. For the midterm, the system operator or another entity could coordinate maintenance scheduling of the generating units in a control area to levelize reliability (e.g., loss-of-load probability) and minimize cost over all hours of the year. In the short term, the operator or another entity could schedule generating units for the week ahead and dispatch those units on a minute-by-minute basis. However, the system operator must manage the transmission grid and some generating units to control frequency and voltage levels to maintain system reliability and stability. This reliability/stability function is mandatory because it is needed to maintain an electrical system and it requires centralized monitoring and control. This chapter and the next one discuss several services implicit in this notion of centralized monitoring and control.

Three ancillary services - unit commitment, economic dispatch, and emissions management-deal strictly with managing assets (primarily power plants) to minimize overall system costs. In all three cases, few resources are required, the cost of providing the service is low, and the economic consequence of not providing the service can be very high.

\section{Unit Commitment}

Unit commitment is a decision-making function in which the system operator attempts to ensure that sufficient generating resources are available to meet customer demands at the lowest possible cost while meeting NERC reliability requirements. The utility uses a combination of personnel, computer models, communication systems, and controls to provide this service.

Unit commitment has several time dimensions, ranging from a few hours to several years. In the broadest sense, unit commitment starts with the initial planning of the generation resources. The least-cost units are selected for construction based upon many factors, including forecast load growth, future fuel prices, and reliability requirements. We do not consider such long-term planning an ancillary service in this report. 
Table 2. Services that the system operator might provide

\begin{tabular}{|c|c|c|}
\hline Service & Time scale & Description \\
\hline $\begin{array}{l}\text { Resource } \\
\text { planning }\end{array}$ & $\begin{array}{l}10 \text { to } 30 \\
\text { years }\end{array}$ & $\begin{array}{l}\text { Develop a least-cost mix of new generating units, } \\
\text { retirements, life extensions, repowering, and demand-side- } \\
\text { management programs }\end{array}$ \\
\hline Fuel planning & 5 to 10 years & $\begin{array}{l}\text { Develop least-cost fuel supplies, contracts, and delivery } \\
\text { schedules }\end{array}$ \\
\hline $\begin{array}{l}\text { T\&D } \\
\text { planning }\end{array}$ & 5 to 15 years & $\begin{array}{l}\text { Design system additions to maintain reliability and to } \\
\text { minimize cost }\end{array}$ \\
\hline $\begin{array}{l}\text { Maintenance } \\
\text { scheduling }\end{array}$ & 1 to 3 years & $\begin{array}{l}\text { Schedule interutility sales and planned equipment } \\
\text { maintenance to maintain reliability and to minimize cost }\end{array}$ \\
\hline $\begin{array}{l}\text { Unit } \\
\text { commitment }\end{array}$ & Up to 1 week & $\begin{array}{l}\text { Decide when to start up and shut down generating units, } \\
\text { respecting unit ramp-up and -down rates and minimum } \\
\text { runtimes and loadings }\end{array}$ \\
\hline $\begin{array}{l}\text { Economic } \\
\text { dispatch }\end{array}$ & $\begin{array}{l}\text { Milliseconds } \\
\text { to minutes }\end{array}$ & $\begin{array}{l}\text { Adjust committed units to maintain voltages, frequency, } \\
\text { and the generation/load area-interchange balance at } \\
\text { minimum cost }\end{array}$ \\
\hline $\begin{array}{l}\text { Automatic } \\
\text { protection }\end{array}$ & Instantaneous & $\begin{array}{l}\text { Minimize damage to equipment and service interruptions } \\
\text { caused by faults and equipment failures }\end{array}$ \\
\hline
\end{tabular}

Source: adapted from Hobbs (1994)

On an annual basis, the system operator coordinates maintenance schedules for all of the generating units to ensure that expected loads are met at the lowest cost while maintaining reliability. This scheduling generally takes advantage of the lower loads in the spring and fall but avoids having too many units out of service at any one time. Alternatively, the owners of individual generating units or a third party could coordinate and schedule unit maintenance.

On a monthly and weekly basis, the utility forecasts expected load hour-by-hour and then schedules generation to supply that expected load. This procedure is necessary because some units require several hours to be brought online. The utility selects from among the generation resources available (both facilities that it operates itself and facilities or systems from which it can purchase) to obtain the lowest-cost mix of generation resources. Unit commitment is constrained by unit startup costs, startup times, minimum operating loads, minimum operating times, etc. It can also be constrained by transmission limitations, reliability requirements, and restrictions on the operation of hydro units. Decisions are made as to which units should be used throughout the week, which units should be kept warm for possible use, and which units can be turned completely off. 
The weekly schedule is usually reexamined daily to determine which units to bring onand offline to serve the expected load for the following day. This process primarily accommodates an updated forecast of the following day's load (based largely on a better weather forecast). It also accommodates changes in unit availability (caused by forced outages or early returns to service). Changes in the external power market can also influence the unit commitment if someone unexpectedly has power for sale at a low price or may be willing to pay a high price for additional power.

These functions do not have to be performed by the owner of the generation equipment; they can be performed by anyone with sufficient information about the costs of each unit, communications links among generating units and transmission-system components, expectations for the load, reliability requirements, and transmission-system configuration and constraints.

Unit commitment is not strictly a necessary service because power can be delivered reliably without least-cost scheduling. Without it, however, the cost of electricity will likely be higher. The cost of coordinated scheduling is low relative to its benefits because it is a decisionmaking function with few equipment expenses (other than computers, monitors, and telemetry equipment) and a small number of people involved. This service could be priced on a demand $(\mathrm{kW})$ or energy $(\mathrm{kWh})$ basis or as a fixed charge.

Customers who use the service are readily identifiable by the type of service contract they have. System customers automatically use the service. Conceivably, a competitive market could perform essentially the same function via bilateral contracts, although this would require a great deal of communication among each of the generators and customers.

\section{Economic Dispatch}

Economic dispatch is a continuous real-time decision-making function in which the system operator, given the actual mix of generating units and power purchase/sell opportunities, attempts to meet current customer demands at the lowest variable cost while meeting NERC reliability requirements, emissions restrictions, and the terms of customer and interutility contracts. The system operator adjusts the output from each unit to minimize the total variable cost of generation.

In addition to scheduling units to meet the utility's own demand, the system operator may coordinate with the operators in other utilities. Most utilities are members of a power pool for the purpose of sharing emergency and reserve responsibilities. This sharing improves reliability by allowing a utility to call on its neighbors for assistance during local emergencies. Some power pools extend coordination to include joint economic dispatch of some or all the units in the pool. In addition, the system operator can engage in economy transactions with other utilities separate from any pool dispatch. All these activities ensure that the least-cost units are used to provide power throughout a region larger than a single utility. 
The unit-commitment, economic-dispatch, and emergency-protection functions are currently performed centrally on a utility or power-pool basis for the benefit of all customers. Utilities in "tight" power pools plan and operate their individual generation and transmission systems as a single system. There are three "tight" power pools operating today: the New England Power Pool (NEPOOL), the New York Power Pool, and the Pennsylvania, New Jersey, Maryland pool (FERC 1994b). Looser pools perform some of these functions for their members.

Economic dispatch is not strictly a necessary service, because power can be delivered reliably without least-cost dispatch. Without it, however, the cost of electricity will likely be higher. The cost of economic dispatch is low relative to its benefits because it is a decisionmaking function with few equipment expenses (other than computers, monitors, and telemetry equipment) and a small number of people involved. Like unit commitment, this service could be priced on a demand $(\mathrm{kW})$ or energy $(\mathrm{kWh})$ basis or as a fixed charge.

Similar to unit commitment, customers who use economic dispatch service are readily identifiable by the type of service contract they have. System customers automatically use the service.

It is conceivable that a free market could perform essentially the same function via bilateral contracts. This practice would require significantly more communication among generators and customers and might not be practical. For example, NEPOOL recalculates the appropriate output for each generating unit every two minutes.

Emissions Management

With the passage of the 1990 Clean Air Act Amendments and the establishment of allowance trading, utilities moved into an era of economic management of emissions. Rather than simply establishing standards for devices (as with automobiles) where total emissions would still be unlimited if new sources were added, the U.S. Congress placed limits on total emissions. This approach encourages polluters to find the least-cost ways to cut emissions. Emissions can be dispatched as part of economic dispatch. Creation of an allowance-trading market allows for the coupling of emissions management and economic dispatch.

As with unit commitment and economic dispatch, emissions management is a decisionmaking function with few resources required but with large impacts on the economics of electricity generation. While not strictly necessary, the economic consequences of failing to perform the function are significant because the penalties for exceeding allowance limits are severe. Standards for allowance limits are enforced by the U.S. Environmental Protection Agency. The dispatching agent would likely charge for this service on the basis of $\phi / \mathrm{kWh}$ or $\$ /$ ton of emissions. 


\section{RESERVE GENERATING CAPACITY}

Because utility equipment (generators, transmission lines, etc.) is not $100 \%$ reliable and because it is not possible to predict what future loads will be with $100 \%$ accuracy, utilities keep extra generating capacity available in reserve. These reserves are split into categories based upon how rapidly they can respond. Below, we classify generation reserves as load-following spinning, reliability spinning, unscheduled energy, supplemental operating, stability enhancement, time correction, local-area security, and nonoperating (Table 3). As the electric industry evolves, customers and suppliers may choose to aggregate some of these reserve functions.

Table 3. Types and uses of reserve generating capacity

\begin{tabular}{|c|c|c|}
\hline Type & Description & Unbundled? $^{\mathrm{a}}$ \\
\hline $\begin{array}{l}\text { Spinning reserve } \\
\text { - Load-following } \\
\text { - Reliability }\end{array}$ & $\begin{array}{l}\text { Fully available within } 10 \text { minutes } \\
\text { - Used to meet time-varying customer loads } \\
\text { - Used to compensate for generator outages }\end{array}$ & $\begin{array}{l}\text { Yes } \\
\text { No }\end{array}$ \\
\hline $\begin{array}{l}\text { Unscheduled- } \\
\text { energy reserve }\end{array}$ & $\begin{array}{l}\text { Used to make up discrepancies between scheduled } \\
\text { power deliveries and customer use and actual power } \\
\text { deliveries and customer use }\end{array}$ & No \\
\hline $\begin{array}{l}\text { Supplemental } \\
\text { operating reserve }\end{array}$ & $\begin{array}{l}\text { Used to meet unplanned generating requirements in } \\
10 \text { to } 30 \text { minutes }\end{array}$ & Yes \\
\hline $\begin{array}{l}\text { Stability } \\
\text { enhancement }\end{array}$ & $\begin{array}{l}\text { Used to maintain dynamic stability of the electric } \\
\text { system }\end{array}$ & No \\
\hline Time correction & $\begin{array}{l}\text { Used to ensure that electric-system frequency } \\
\text { averages } 60 \mathrm{~Hz}\end{array}$ & No \\
\hline Local-area security & Used to compensate for local transmission constraints & No \\
\hline $\begin{array}{l}\text { Nonoperating } \\
\text { reserve }\end{array}$ & $\begin{array}{l}\text { The difference between total capacity and that needed } \\
\text { to meet planned system peaks plus other reserves }\end{array}$ & Yes \\
\hline
\end{tabular}

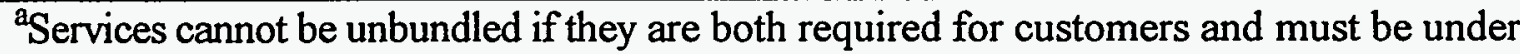
the control of the system operator.

Some generation is kept online and operating (i.e., spinning) so that it can begin responding to imbalances between generation and load within seconds. Such generation, which can reach full output within 10 minutes, is used for two purposes. Load-following spinning reserve is needed to follow fluctuations in customer loads. Reliability-spinning reserve is required to be instantaneously available in the event that generation or transmission equipment fails. Although there are many similarities between these two spinning reserves (both immediately respond to an imbalance between load and generation), we make a distinction here because they differ in the service they provide to customers and suppliers and in which customers require them. 
Generation may also be kept online to provide local-area-security, time-correction, and stabilityenhancement services, which are discussed later in this section.

Generating units differ in their ability to provide these spinning-reserve services. Some equipment is quite valuable because it can change output very quickly. For example, the proposed Mt. Hope pumped-storage project will be able to ramp up at $210 \mathrm{MW} / \mathrm{sec}$ (Liodra and Depenbrock 1994). By comparison, a baseload steam plant might require several minutes to change output by this amount. Some renewables, such as wind and photovoltaics, are intermittent and therefore cannot be dispatched at all. Such generators may impose a spinning-reserve burden on the system, much as a time-varying load does.

Additional generation capacity is kept available and ready to be online beyond ten minutes if the spinning reserves prove to be inadequate. This reserve is called supplemental operating reserve, and it is intended to be fully available within 30 minutes of need. As with spinning reserves, supplemental reserve could be split into load-following and reliability components but we have not done so.

Still more generating resources need to be available over a longer time if either the load grows unexpectedly (e.g., because the local economy is growing rapidly) or a major failure occurs. Planning and constructing additional generating facilities takes significant time, from as short as two years for small gas turbines to as long as a decade for a large coal unit. Thus, it is necessary to have additional generating facilities available that can be called upon if they are needed. Also, not all generating units are operational all the time. Periodically, units need to be taken offline for planned maintenance, and units occasionally suffer unexpected (forced) outages. Thus, available capacity is always less than installed capacity. The installed reserve minus the capacity dedicated to the spinning, unscheduled-energy, supplemental-operating, stabilityenhancement, time-correction, and local-area-security reserves is available to fill this need (Fig. 3).

While it may be tempting to think of a particular generator as providing a particular service, it is generally preferable (for reliability reasons) to spread services over several generators. A 500-MW unit might dedicate $400 \mathrm{MW}$ to basic energy production and leave 100 MW for a combination of load-following spinning reserve, reliability spinning reserve, serving unscheduled energy, stability enhancement, and time correction.

\section{Load-Following Spinning Reserve}

Utilities must supply energy whenever customers require it, generally with no advance warning from customers; we expect the light to turn on as soon as we flip the switch. Aggregating customer loads yields a total load that behaves in a statistically predictable manner, greatly reducing fluctuations but not eliminating them (an example of the law of large numbers). To accommodate the fluctuations in load, utilities dedicate a portion of their online generation to providing load-following spinning reserve (sometimes called regulating margin). The output of this generation is adjusted continuously and automatically to compensate for these changes in 
CAPACITY AND DEMAND (MW)

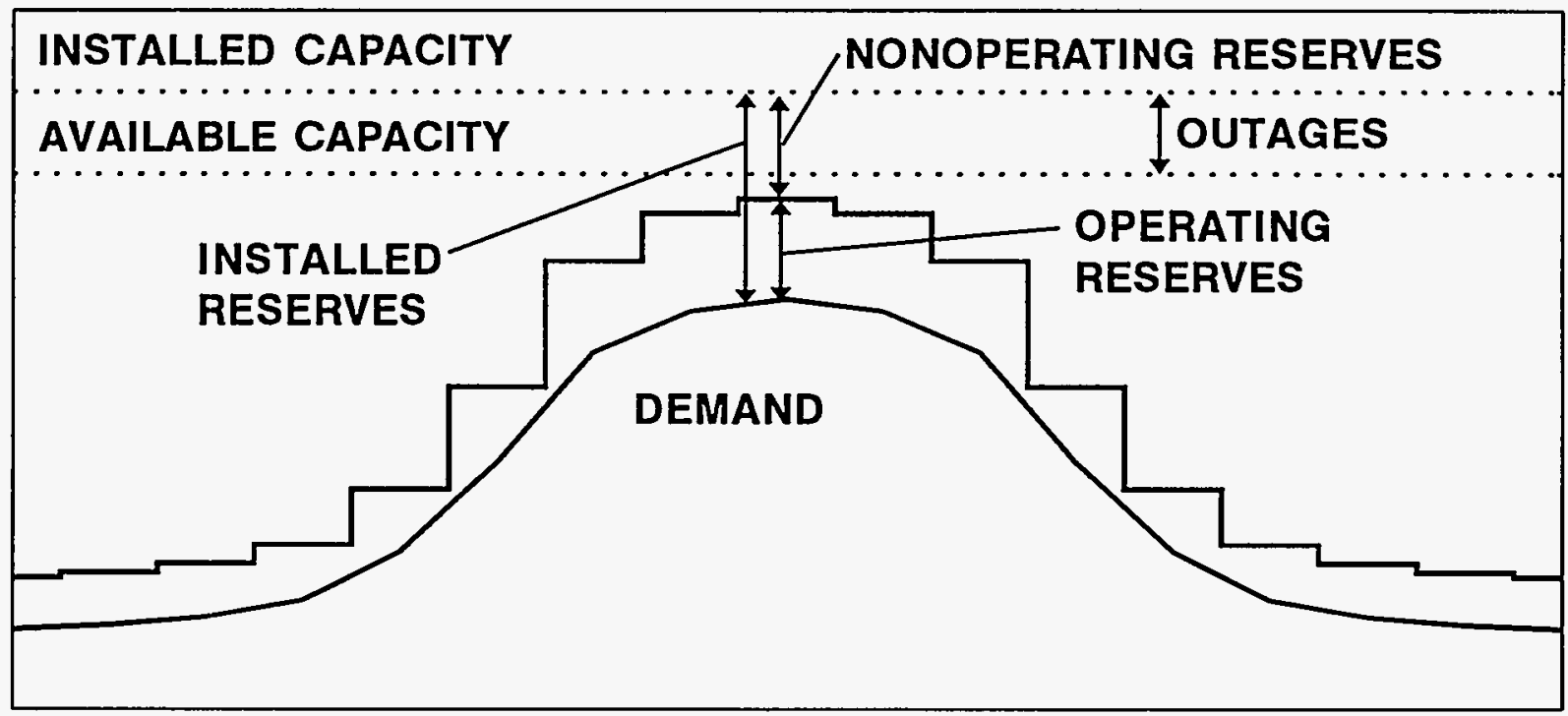

Fig. 3. Schematic showing temporal variation in loads and generating capacity. Operating reserves include both spinning reserves and supplemental operating reserves. Outages include both forced outages and planned maintenance outages.

the aggregated customer load. Appendix A describes how utilities control generation to provide both load-following spinning reserve and reliability spinning reserve.

This service is required by most customers. A customer could completely avoid placing a load-following burden on the utility by always presenting a constant load to the utility. All the information required to provide this service is available at the customer meter. This could be accomplished by strictly controlling the load, by having energy storage available, or by having dedicated generation compensate for load fluctuations. This storage or dedicated generation could be owned by the customer or could be contracted for directly by the customer. Load can be metered to ensure compliance with utility requirements; the utility likely would impose a penalty if the customer failed to control its load.

Under NERC guidelines, load-following spinning reserve is spread over as many units as is practical because it is easier to get the required rapid response by adjusting several units a small amount rather than by adjusting a single unit a large amount. Any generating unit within the control area equipped with a governor and automatic generation control (AGC) can help provide this service.

Each NERC region sets the required amount of load-following spinning reserve that a utility must provide. This reserve is normally sized to meet the historical maximum absolute 
deviation of actual load from expected load for a scheduling period (e.g., an hour). The sum of load-following spinning reserve and reliability spinning reserve is based on the size of the largest generating unit (typically 3 to $6 \%$ of the expected peak load). The cost of providing the service is a combination of the fixed costs of the generating units plus the variable costs for the actual energy provided. This reserve is used regularly. The cost of this service will depend on the actual units used to provide this service. If spinning reserves are provided by the unused portion of operating units, the cost will be low. On the other hand, if spinning reserves are provided by units that are kept hot but are delivering minimum power to the grid, the cost could be much higher.

Billing for this service should probably be based on the volatility of the customer's load (e.g., the standard deviation of the load). An interesting question concerns the appropriate time period over which to determine such temporal variations. The usual 30- or 60-minute interval may be too long to capture the effects of load volatility on utility costs. As shown in Fig. 4, different customers impose different costs on the utility, depending on the variance of the customer's load. In this example, it costs the utility more to meet the time-varying loads of Customer 1 than to meet those of Customer 2 . For example, electric-arc furnaces impose enormously variable loads on utilities. These variations not only require additional generation and transmission capacity, but they also stress equipment, reducing operating lifetimes. Paper mills, on the other hand, operate with nearly constant loads, thereby requiring much less load-following reserve.

\section{Reliability Spinning Reserve}

Reliability spinning reserve is required because utility equipment is not $100 \%$ dependable. When failures occur, either of generators or of transmission components, additional generation must be online (spinning) to respond immediately and to continue to meet the load. The way this spinning reserve is controlled is essentially identical to the way load-following spinning reserve responds. Both detect and respond to discrepancies between generation and load. An important difference is that load-following spinning reserve is responding all the time to small changes in system load while reliability spinning reserve responds to infrequent, but usually larger, failures of generation or transmission (Appendix A).

One of the major benefits of interconnections with other neighboring utilities is the reduction in required reliability spinning reserve. If each utility stood on its own, each would have to be able to survive the loss of its largest generating unit at all times. For a utility with few units, this need would represent a significant expense and a significant restriction on the use of larger, cheaper, units. Interconnected utilities need only be able to survive the loss of the largest unit in the interconnection. Additional generators, beyond those required for the expected peak load and customer load fluctuations, are kept online to accomplish this.

Under NERC guidelines, reliability spinning reserve is spread over as many units as is practical because it is easier to get the required rapid response by adjusting several units a small amount rather than by adjusting a single unit a large amount. Any generating unit equipped with a governor and AGC can help provide this service. 


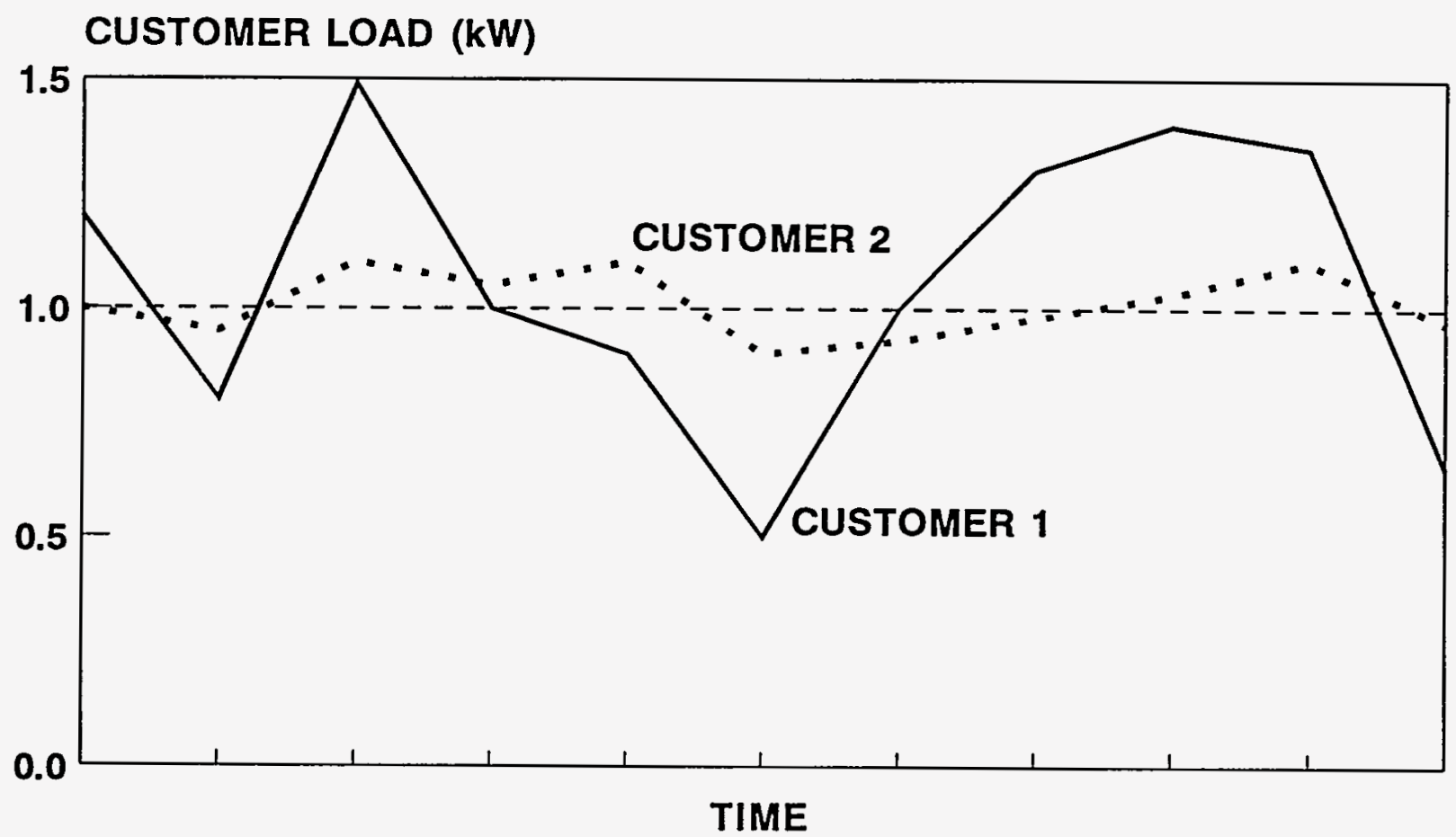

Fig. 4. The temporal nature of customer loads can differ substantially. These differences affect the utility's cost of service, especially for load-following spinning reserve.

With sufficiently sophisticated controls, a customer might also help supply reliability spinning reserve to the system by allowing automatic tripping of part or all of its load. Communications between customer and supplier may allow for tripping of the customer's load in response to loss of the supplier's generating units. Alternatively, underfrequency relays, installed just upstream of a customer's load, may be set to detect small changes in system frequency. If the frequency drops below a set level (e.g., $59.9 \mathrm{~Hz}$ ), the customer's load is automatically disconnected from the grid. Only the system operator, however, has sufficient information available (interchange flows as well as frequency deviation) to know if the reliability problem is inside or outside the control area and how much response the control area should provide to the event (see Appendix A). In this sense, the system operator provides the reliabilityspinning reserve even though he may contract with generators and loads for the resources to provide the service under his control.

The required amount of reliability spinning reserve for a utility is set by each NERC region, varies among control areas, and is tied to the size of the shared risk of losing the largest generating unit. The cost of providing the service is a combination of the fixed and operating costs for keeping the generating facilities online and unloaded. This can include the differential in cost of having to operate more-expensive generating units to maintain sufficient capacity.

The billing for this service would probably be based on peak demand, either the customer's maximum demand or the demand at the time of system peak. 


\section{Unscheduled Energy}

If a customer takes more energy from the grid than has been contracted for, the utility must either supply the energy or have sufficient control over the load to be able to stop the excess consumption. Because of the difficulty in controlling each load and because the unplanned consumption may be caused by an emergency, utilities are reluctant to automatically cut off customer loads.

Historically, unscheduled energy was not an issue because vertically integrated utilities generally agreed to meet all their customers' electrical demands. In the future, if customers obtain generation capacity and energy from sources other than their local utility, unscheduled energy could be an issue.

Instead of controlling the load directly, utilities could charge a high price per $\mathrm{kWh}$ for this unplanned service. The high price would discourage customers from "leaning on" the system and ensure that customers and their suppliers meet their contractual obligations. Alternatively, customers could buy standby service from their local utility. Technically, this service is the same as load-following spinning reserve; but, contractually it is quite different.

Because metering use of this service is easy, billing could easily be based on a penalty for use. Alternatively, it could simply be a requirement that all customers contract for some level of load-following spinning reserve.

\section{Supplemental Operating Reserve}

Utilities maintain additional generation reserves to cover times when the spinning reserves are insufficient. Such reserves are expected to be available within 10 to 30 minutes. Each utility's supplemental operating reserves are set by its NERC region and generally total about $3 \%$ of the expected daily peak load. These reserves not only back up spinning reserves but are also used to restore the generating mix to a least-cost configuration. Any generating unit or interruptible load could help supply this service if it is available within 10 to 30 minutes. Only the system operator, with his knowledge of all of the conditions within the control area, knows when and how much supplemental reserves are required.

The cost of providing the service is a combination of the fixed costs for providing the generating facilities and any operating costs associated with being able to operate on 10-minute notice. This expense could include the differential cost of having to operate a more expensive unit to maintain sufficient capacity or a unit that could be started by remote control (a hydro unit for example). Because of the similarity between spinning and supplemental reserves, the billing for this service would likely use the same method as that used for spinning reserves. 
Stability Enhancement

Almost all power-system generators operate synchronized to the power-system frequency of $60 \mathrm{~Hz}$. Consequently, all of the generators operate in lock step with one another. When a short circuit or fault occurs on the transmission system, the generating units closest to the fault cannot transmit their full output through the short circuit and begin to speed up. When the fault is cleared and the transmission system re-established, these machines are no longer in step with the rest of the machines in the system and must be slowed down to be brought back into synchronism. If the transmission system is capable of handling the resulting power-flow surges, the errant generators will return to normal, and the disturbance will pass. If the transmission system is too heavily loaded to handle the surge, the generators will continue to speed up and will have to be tripped off the system to prevent being damaged, causing a loss of generation and another disturbance as the reliability spinning reserves are called upon.

The obvious cure for inadequate stability is additional transmission capacity, although this remedy may be difficult and expensive. Active devices installed on the generator can enhance system stability in various ways, often at costs considerably less than building additional transmission capacity. The benefit received is usually specific to the location of the stabilizing device in the system and the type of stabilizing device employed.

These devices can damp out oscillations by rapidly injecting and/or removing either real or reactive power from the system in a controlled manner. (Appendix B explains reactive power.) Fast throttling, dynamic brakes (i.e., a resistor brake to slow down the generator, absorb energy, and prevent the unit from pulling out of step with the rest of the system), voltage regulators, and field-forcing devices called power-system stabilizers all can be placed on generators.

Storage devices such as superconducting magnetic energy storage devices (SMES), batteries, or flywheels with high-speed, solid-state controllers can be used. Transmission-system devices, such as static-var compensators, DC lines, DC-DC links, and flexible AC transmission devices, can all be used to dampen oscillations if they have appropriate controllers. A load with a large solid-state drive could be equipped with a controller that stabilized the power system without detriment to the controlled load. For most of these devices, at least a portion of the capacity would have to be dedicated to stabilizing the power system and would be unavailable for other uses. All these devices must be able to respond automatically and extremely rapidly (within a few cycles) to dampen power-system oscillations and other short-term disturbances, such as surges, sags, swells, and notches in the voltage and current waveforms. (See the discussion of power quality in Chapter 4.)

The stability benefits provided by various devices can be determined through systemstability studies. Such studies can determine the limits on operation of each generator and the transmission system under various conditions. The provider of the service could be compensated based on the economic benefit the stabilizing device provides to the system. This compensation could be a share in the energy cost savings or a reimbursement for the increased reliability. In 
most cases, the benefits would be specific to the particular power system and the location within the system where the device was installed.

Such services could be provided by the transmission system, generators, or loads. Anyone with capital to invest in the device and access to an effective location on the system could provide stability services. Ultimately, the system operator would decide how much of what services are required and how much they are worth to the system.

\section{Time Correction}

Most electric clocks operate by counting the cycles in the power frequency. Although the frequency is maintained within tight limits (often within $0.01 \mathrm{~Hz}$ of the $60-\mathrm{Hz}$ reference), the apparent time displayed by power-system-supplied clocks would drift if not corrected. A $0.01-\mathrm{Hz}$ average error would cumulate to 15 seconds a day. Generation must be adjusted periodically to correct for this error.

American Electric Power, Southern California Edison, and the North Texas Security Center monitor real and apparent time for the eastern interconnection, the western interconnection, and Texas, respectively. When the difference between real and apparent time reaches two to eight seconds, the time monitor notifies each control area in the interconnection. All control areas then adjust their frequency setpoint of the AGC by $0.02 \mathrm{~Hz}$ from $60 \mathrm{~Hz}$ (up if apparent time is behind real time or down if apparent time is ahead of real time). The frequency set point is returned to $60 \mathrm{~Hz}$ when real and apparent time are once more synchronized. This is a small, inexpensive, but important service.

Time correction is a mandatory service that can be provided only by the system operator and therefore cannot be unbundled. However, its cost is very small.

\section{Local-Area Security}

A theoretically optimum economic dispatch may not be achievable because of transmission constraints (i.e., voltage, thermal, or stability limits), sometimes referred to as congestion. The lowest-cost production may come from a remote plant whose energy must be imported into the load center over long-distance transmission lines. If the transmission system is composed of a few high-capacity lines, loss of one of these lines may limit the import capacity to the point that service reliability may be unacceptable. To resolve this problem, a utility may reduce output from low-cost but remote units (said to be constrained off) and, instead, operate more expensive generation units near the load center (said to be constrained on) to provide backup for the transmission system. Generation required to be in service for this reason is said to be providing local-area security. The exact nature of the constraint and the available remedies are very case specific.

Any properly located generator can provide local-area security. If the transmission limitation is thermal rather than stability, customers might help provide the service by allowing 
loads to be automatically interrupted, but it is generally only the system operator who has sufficient information to know when control actions are required. ${ }^{*}$ Compensation for local-area security might be based on the difference in cost to operate the constrained-on units relative to the cost to operate the constrained-off units.

\section{Nonoperating Reserve}

Because it takes several years to construct new generating facilities, it is important to have sufficient additional facilities available should some of the existing units become unavailable (either because of planned maintenance or a forced outage) or should the load grow faster than expected. The nonoperating reserve is the difference between installed generating capacity and the sum of actual system peak demand and the other reserves discussed in this section. If more electricity consumers have the option of real-time pricing in the future, the amount of reserves needed will likely go down. Price-responsive loads will reduce the need for reserve capacity. Such a substitution of economics for engineering in setting reliability margins would also reduce the need for the spinning-reserve services discussed above.

The cost of providing this service is essentially the same as the cost of providing basic capacity, and is also based primarily on the construction cost of the generating facilities. If a reserve of $15 \%$ is maintained, then its cost will be about $15 \%$ of the cost of basic capacity. Significant variation can occur, however, because utilities use different types of generators to supply different portions of this service. Generators with lower capital cost but higher operating costs, such as combustion turbines, may reduce the cost of providing this service.

As with basic capacity, nonoperating reserve can be provided by anyone with generating capacity connected to the grid as long as there is sufficient transmission capacity to move the power to the load. This service need not be provided by the system operator.

Customers who have no reliability requirement and who can accurately predict their load well into the future may not require this service. The customer's load would have to be interruptible by the system operator, however, to avoid using the installed reserve when generation or transmission was out of service.

Because this service consists of capacity held out of production, billing for this service could be the same as for basic capacity, based on the highest power consumption (determined by measuring the energy consumption over short periods, such as a half hour) in a month. Billing should not include charges for capacity that are recovered under the other reserve-capacity services.

*Thermal overloads involve the excessive heating of transmission lines or other equipment from excessive flows. Because the limitation is thermal, there is usually time (seconds to hours) in which control action can be taken. Stability limits, on the other hand, involve the inability to keep rotating equipment synchronized. Oscillations can build between generators within a few cycles, allowing little time for corrective action. 


\section{BLACK START}

Auxiliary services for an operating generating unit use about 2 to $5 \%$ of its output. Bringing a generating unit online from a cold start, however, requires considerable electricity to operate motors; perhaps to heat fuel oil; to convey fuel to the boiler; to pump water, steam, and air throughout the plant; and for many other functions. Under normal circumstances, the generating unit draws this power from the grid.

Under conditions of system collapse, it may not be possible to draw power from the grid. Generating units that can restart without taking power from the grid are called black-start units. A unit that is capable of black starting is inherently more valuable to the system. After the unit starts itself, it can be used to start other units and to energize the transmission grid. Some units black start using a small gasoline-driven generator that starts a larger diesel generator. The diesel generator is used to start a combustion turbine that produces sufficient power to provide the auxiliary services for a large fossil steam plant. Some combustion turbines can black start using batteries and compressed air. Some hydro units can black start using only water pressure.

Almost any generator connected to the grid can be used to start other units if it has blackstart capability. Conceivably, emergency generators at a load could be used for this purpose, although it would be a very rare case where this was economically viable.

Black start is yet another service that is vital although inexpensive. Its costs are primarily the capital cost of the equipment used to start the unit, the cost of the operators, the routine maintenance and testing of equipment, and the cost of fuel when the service is required. Because the system requires this service to be viable, all customers who use the system require this service.

Customers could be charged for this service as part of the fee for connection to the grid. Generators that provide this service could be paid a predetermined fee when the service is provided or could be paid annually for being ready to provide the service. 


\section{TRANSMISSION-RELATED ANCILLARY SERVICES}

\section{TRANSMISSION-SYSTEM MONITORING AND CONTROL}

The transmission system is both the means whereby electric service is delivered to customers (through the distribution system) and the linkage among generators to increase reliability, reduce generating costs, and make possible commercial trading in electric power. The system must be monitored and adjusted continuously to accommodate changing flows, voltage levels, and losses within the system and to respond to disturbances, such as lightning strikes and outages. This management is accomplished through the use of central control facilities, computers, communication equipment, sensors, remote actuators, and operators.

Most control centers use sophisticated system simulation and modeling capabilities to conduct what-if analyses for projected system conditions. Computer-based state-estimation analysis tools, which assess the status of the system in real-time, advise the operator when the system is at risk of a disturbance. In some ways, transmission monitoring and control is the transmission-system equivalent of economic dispatch of generation. In fact, to the extent that transmission losses depend on the location of the generation, transmission losses are factored into economic dispatch.

The capacity of the transmission network varies with the location of generation relative to loads, the characteristics of the generation units online, and the availability of system reactivepower-compensation devices. Changes in any one of these factors can change the performance, and therefore the capacity, of the transmission system. Construction of new transmission lines to strengthen the system is increasingly difficult because of public opposition. With the emphasis on access to the system for economic reasons, the importance of the continuous transmissionmanagement function will increase as it is called upon to extract more and more capacity from a finite resource.

Flows in the transmission network change continuously as generation and loads change. In general, power flows through many paths when moving between two points. The flows along different paths are inversely proportional to the impedance of each path. Contract arrangements, on the other hand, often specify only a single path. Parallel flows that spill over onto the lines of a third party can impose a burden on the third system. Such unplanned power flows, often called loop flow, can fill a transmission line's capacity, blocking the flow of electricity from other sources. The Bonneville Power Administration (1994) notes that unscheduled power flows from 
the Southwest into California and on to the Northwest have forced Bonneville to purchase highercost power from other sources.

Flows must be monitored continuously to ensure that lines are not overloaded and that connectivity is maintained. Automatic equipment protects individual lines from damage by removing them from service when flows are excessive. This protects the line in question but frequently results in overloading other lines. Unfortunately, there are few devices on the transmission system (exceptions include DC lines, back-to-back DC links, phase-angle regulators, and flexible-AC transmission-system devices) that allow direct adjustable control of the flow over a single line. Consequently, the system must be monitored and configured to accommodate changing conditions. When the transmission system cannot be configured to accommodate the required flows, generation must be taken off economic dispatch and adjusted. (See the discussion of local-area security in Chapter 3).

Operators have some discretion in system configuration. Overall system performance can sometimes be enhanced by removing a line from service or by opening a connection. If a lowcapacity line runs parallel to a high-capacity line, it may be better to remove the low-capacity line from service and allow the high-capacity line to carry all of the load if the low-capacity line is reaching its limit.

Moving power over long distances always results in real and reactive power losses; see Fig. 5 and Appendix B. Loss management is performed both in planning and in operating the transmission system. As with generation, designers must trade off the savings associated with lower losses against the higher capital costs of larger or better transmission-line conductors that have less resistance or more-efficient transformers. Losses are a function of the patterns of load and generation. System operators can generally configure the network to minimize losses on a daily basis. For example, high-loss network elements (transformers or lines) can be taken out of service to force flows onto lower-loss elements when the capacity of the high-loss element is not required. The optimal configuration can change as generation and load patterns change.

The operators, in the event of a sustained transmission contingency (the loss of a line or another element in the transmission system), reconfigure the system to achieve two goals: (1) prevent overloading other elements of the system and (2) minimize the number of customers that experience an outage. ${ }^{*}$ The effectiveness of these control actions depends on the flexibility built

*The length of time available for this decision depends on the overload condition the operator is trying to mitigate. If the load on an overhead line has just passed its normal rating but not yet reached its emergency rating, the operator may safely wait a few hours before taking action. A line's 24-hour emergency rating might be 10 to $30 \%$ higher than its normal thermal limit, while its 15 -minute emergency rating might be 20 to $100 \%$ higher than its normal thermal limit. With a transformer or an underground cable, a decision may be required in minutes. Of course, if the overload is severe enough, the protective relaying will automatically remove the equipment from service and present the operator with a new and potentially more difficult situation. 
into the system. Flexibility is a function of the quality of the planning (inexpensive) and the redundancy built into the system (expensive).

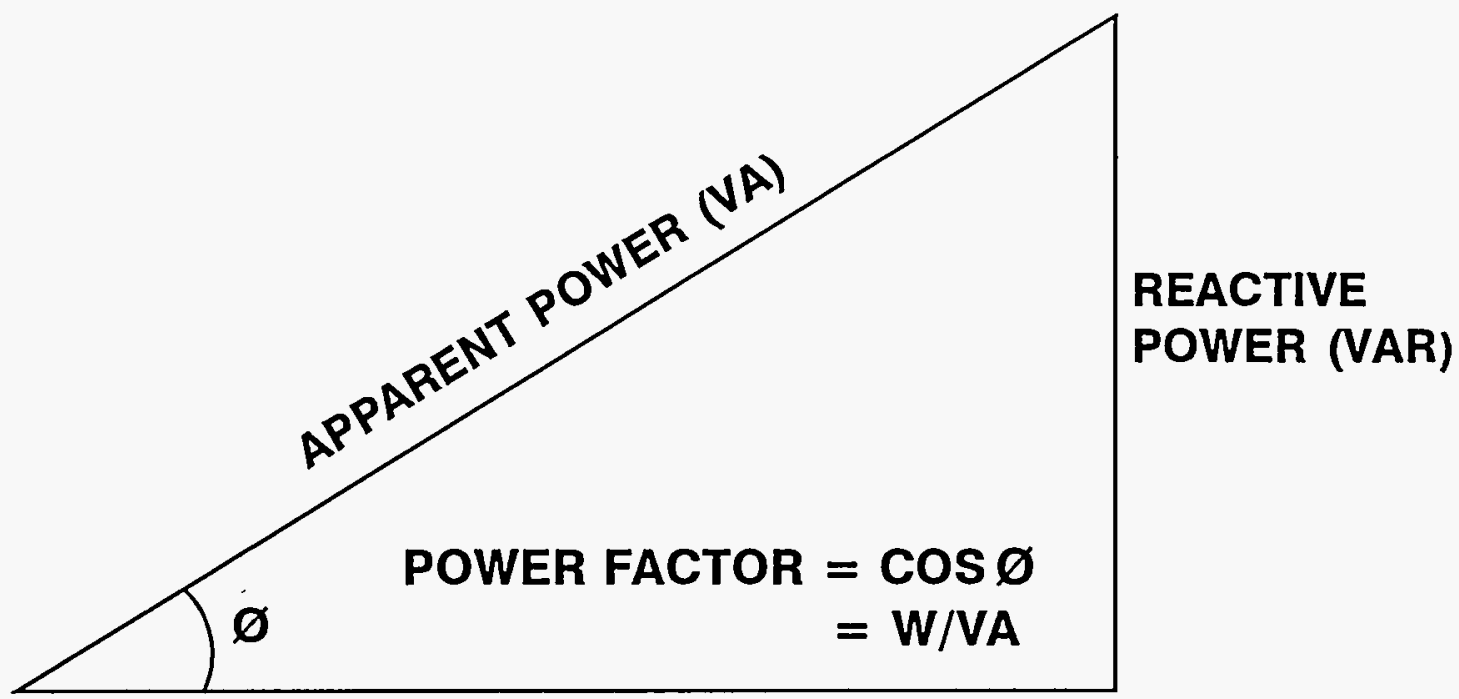

\section{REAL POWER (W)}

Fig. 5. Apparent power is the vector sum of real and reactive power.

Transmission monitoring and control are necessary for the continued safe, reliable operation of the electrical system and will become even more important to maximize use of transmission capacity for power transfers. Compared to generation, monitoring and control are inexpensive. All customers implicitly use this monitoring and control service whether the response is to adjust the system and maintain their load or to interrupt their load in an effort to help the system. Billing for this service could be on a peak-kW basis.

\section{REAL-POWER-LOSS REPLACEMENT}

Real power losses are the differences between generated real power and the real power delivered to customers. Moving power over long distances always results in real losses because of the resistance of each element. The losses depend on the network's configuration, the generators, and the loads.

*For current-carrying elements, such as transmission lines, the loss is proportional to the square of the current flowing through the conductor times its resistance $\left(I^{2} \mathrm{R}\right)$; these are called load losses. For shunt devices (placed from line to ground or from line to line), such as capacitors or inductors, the loss is proportional to a power of the voltage across the device divided by its resistance $\left(\mathrm{V}^{\mathrm{n}} / \mathrm{R}\right)$, where $\mathrm{n}$ depends on the nonlinearities of the device); these are called excitation losses. Devices like transformers have both load and excitation losses. 
Losses are composed of the excitation and load losses of each element. Excitation losses are voltage dependent and essentially load independent. Load losses for most devices are a function of the square of the load. For a typical transmission system, losses average 2 to $3 \%$ of the system load. However, losses vary greatly as conditions on the network change. In particular, at times of system peak demands, losses are much higher than under average loading conditions (Fig. 6). The nonlinear nature and temporal variations in losses make it difficult to compute their costs and to assign them unambiguously to particular customers.

Real power losses must be made up by generators. The system operator could run its own generators to compensate for the losses, he could contract with another supplier to provide for the losses, or customers could contract with other suppliers to provide for the losses. Retail customers usually pay for losses on a system-wide basis. Point-to-point transaction customers (where a customer contracts with the system operator to move a block of power from one point to another) can either pay the system operator for the losses or they can supply extra power to make up for system losses.

Typically, energy losses are paid for on a $\not / \mathrm{kWh}$ basis and vary with time based on the variable operating costs of generating units. Demand losses are paid for on a $\$ / \mathrm{kW}$-month basis and reflect the costs of additional generating and transmission capacity. Determining costs and prices is complicated because transmission-system losses are functions of both time and location. ?nly the system operator has sufficient information to know what the losses are at any time.

\section{LOSSES AS PERCENT OF MONTHLY SYSTEM PEAK}

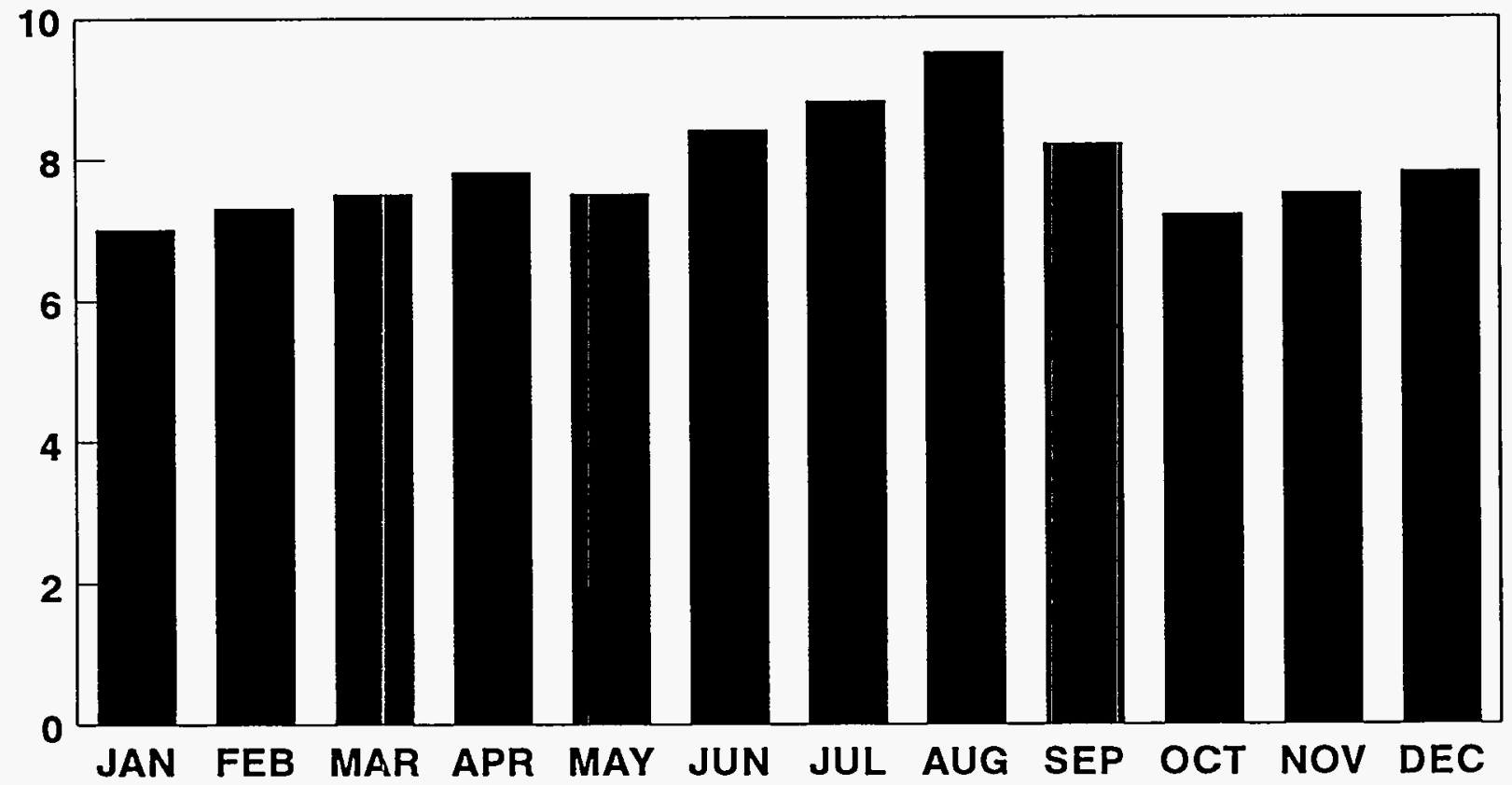

Fig. 6. Transmission and distribution losses for the Detroit Edison system at the time of monthly system peaks (Matusz 1994). 


\section{REACTIVE-POWER MANAGEMENT AND VOLTAGE REGULATION}

Because of the inductive nature of most power-system devices and most loads, reactivepower management and voltage regulation are two aspects of the same problem. Reactive power refers to the portion of apparent power that does no work (Appendix B). Reactive power must be available to operate certain kinds of equipment (e.g., transmission lines, transformers, motors, and fluorescent lamps) and to maintain voltage levels, reduce losses, and control the phase angle between voltage and current within the transmission and distribution system. Reactive power is consumed both by the transmission system and by customer loads. Apparent power is the complex sum of real power (the portion that produces work) and reactive power (Fig. 5).

Reactive-power management and voltage regulation include both system and local components. System reactive-power management and voltage control is used to maintain voltages within prescribed limits at various points in the transmission grid and to compensate for the reactive requirements of the grid. In that sense, it is analogous to reliability spinning reserve. We consider local reactive-power management and voltage regulation to be a customer service, intended to: (1) meet customer reactive-power needs and (2) control each customer's impact on system voltage and system losses and ensure that power-factor problems at one customer site do not affect power quality elsewhere on the system. In that sense, local reactive-power management and voltage control is analogous to load-following spinning reserve.

Reactive losses are much higher than real losses. Voltage drops are predominantly caused by the inductance of the lines and transformers (rather than the resistance), and can be compensated for by supplying reactive power. (Conversely, too much reactive power can produce excessively high voltages.) Because of the high inductance of lines and transformers, reactive power does not travel well through the transmission system, so reactive support must be provided much closer to reactive loads than real power needs to be provided to real loads.

Voltage regulation is aimed primarily at maintaining voltages within certain ranges, but is also concerned with minimizing temporal variations in voltage. Voltage regulation is generally more of a local problem than is provision of real power for the reasons given above. Finally, most devices (lines, transformers, breakers, etc.) are load limited by current rather than by real power. If they are carrying significant reactive power and reactive current, they have less capacity available to transport real power.

Most customer and utility equipment is sensitive to the power-supply voltage. Regulating bodies and standards-setting institutions (such as the Institute of Electrical and Electronics Engineers, NERC, the NERC regions, and state regulatory commissions) establish the range of acceptable voltages to be delivered to customers. For example, voltages delivered to residential customers are typically maintained in the range of 110 to $130 \mathrm{~V}$. Most utilities set standards for voltages throughout their transmission system whether a customer is connected at the point or not. 
Historically, power has generally been sold, either between utilities or to ultimate customers, at a specified minimum power factor (the ratio of real power to apparent power). Once the customer has fulfilled its power-factor obligation, the utility is responsible for maintaining system voltage. While this process may remain the most effective way to split responsibilities between customers and suppliers, in many instances the distinction does not necessarily lead to the most efficient use of resources. ${ }^{*}$ We split the services into a local component and a system component because the customer has sufficient information at its location to control both local reactive-power demand and the local voltage while only the system operator has sufficient information to know what the voltage regulation and reactive-power requirements are throughout the grid.

The cost of supplying reactive power is primarily the capital cost of the equipment (e.g., generators and capacitors). In addition, the operating cost of over- or under-excitation of generating units should be assigned to reactive support. Voltage-control devices have additional operation and maintenance expenses and generally have higher capital costs as well.

System Reactive-Power Management and Voltage Regulation

Voltage is controlled throughout the transmission system through the application and operation of ratio-changing devices (e.g., transformer taps and voltage regulators) and reactivepower-control devices (e.g., capacitors, reactors, static-var compensators, generators, and occasionally synchronous condensers). The system operator must monitor and control these voltages and supply the reactive-power requirements of the grid. At certain locations, it may be more economic for the utility to purchase reactive support from a customer or other party than it is for the utility to directly supply the reactive support it is responsible for (i.e., the customer could sell VARs to the system operator).

Because the cost of supplying system reactive power management and voltage regulation is primarily a capital cost, billing could be tied to customer peak demand.

Local Reactive-Power Management and Voltage Regulation

The customer can correct the power factor of its load and control its voltage through the application of reactive-power-control devices (usually capacitors but possibly reactors, synchronous motors, synchronous condensers, static-var compensators, or customer-owned generation). If the customer is unable to perform this function, the supplying utility can provide

*A lightly loaded transmission system might require the application of inductors at local substations to keep voltages from being excessive. The traditional split in responsibilities that requires customers to meet minimum power-factor standards while utilities control voltage would require a poor power-factor customer to install capacitors to raise its power factor at the same location the utility was installing inductors to control voltage. 
reactive power from devices installed on the transmission and distribution system. Some utilities charge customers for reactive-power consumption at $20 \%$ of the rate charged for real power consumption.

\section{TRANSMISSION RESERVES}

Just as generation capacity is required for spinning reserve, frequency regulation, area control, and automatic generation control, so must reserve capacity be available on the transmission system. This extra transmission capacity is used to provide instantaneous accommodation to replace the output from a disabled generator with generation from units in other locations. Primarily because transmission systems are passive, we do not divide transmission reserves into different elements, as we did for generation reserves.

Sufficient reserve transmission capacity must also exist to handle the increased flows resulting from the outages of lines or transformers. Most transmission systems are designed and operated so that they can survive the removal of any single element without loading any other element above its emergency rating. System engineers refer to this as the $\mathrm{N}-1$ criterion, where $\mathrm{N}$ refers to the number of generation and transmission elements being considered.

Customers who require generation reserves also require the corresponding transmissionreserve services. Because there is generally no load associated with these services there are few losses. The primary cost of transmission reserves is the capital cost of the required equipment; additional costs are associated with planning, monitoring, and maintaining the system.

Only customers with no reliability requirement at all do not require the extra transmission capacity, but even they require the system operator to monitor the transmission system, identify the need to take action, and take the control actions to interrupt their load. The loads of such customers would have to be automatically interruptible to avoid using the transmission reserve. In that sense, these customers would require the service from the system operator but would also be supplying the system operator with the resource necessary to provide the service.

Billing for this service could be on a peak-kW basis. More generally, payment for transmission reserves is likely to use the same approach as that used for generation reserves.

\section{REPAIR AND MAINTENANCE OF NETWORK COMPONENTS}

In the event of an outage, a maintenance force must be available 24 hours a day, along with an inventory of equipment, to return damaged equipment to service quickly. Some outages require that generators be redispatched (i.e., constrained on or off relative to the order for economic dispatch). This redispatch can be expensive, depending on the duration of the outage. Rarely, transmission outages disconnect customers completely. These outages must be restored 
as quickly as possible, but because the losses incurred are on the customer side, their costs are usually more difficult to quantify.

Preventive maintenance must be performed on all elements of the transmission system to minimize forced outages. Some elements, such as circuit breakers, relays, and transformers, require service every few years. Other elements, such as transmission-line towers, require painting only every decade or two.

All users of the transmission system require this service, although some require more rapid response to outages than others. While the resources for providing the service may be obtained from third parties (e.g., line crews), the service must be centrally coordinated by the system operator with the operation of the rest of the transmission system. Billing would probably be on a peak-kW basis.

\section{METERING, BILLING, AND COMMUNICATIONS}

Individual customer loads are most easily metered at the point of delivery. Interchanges between utilities are metered at the points of interconnection. This function involves construction, maintenance, and regular calibration of complex equipment able to measure high voltages and currents continuously to an accuracy of better than $99 \%$ for years. The equipment must be sufficiently sophisticated to accommodate the various tariffs offered (e.g., time-of-use metering, demand and energy accounting, and real- and reactive-power charges). Billing also requires record keeping and accounting.

All of the generators and loads receiving compensation (or reduced rates) because they are capable of responding to central control require real-time communications. AGC, automatic load-shedding, system-control and data-acquisition systems, operator voice communications, and protective devices all require communications. Many means of communication are used, including microwave, radio, leased telephone line, pilot wire, fiber optics (separately or carried within a power-line conductor), and carrier current coupled directly to the power line. The communications network is frequently integrated tightly into the transmission network.

System customers should pay for the communications required to operate the system. Individual customers should pay for any special metering and communication equipment required for their specific situation. Third-party generators that are compensated for their ability to respond to central control should have that compensation adjusted to the extent that the transmission system provides communication services for them.

As with many of these services, while the cost to the overall system is low, the cost of specific installations can be quite large. In principle, this service need not be provided by the system operator. 


\section{POWER QUALITY (WAVE FORM)}

Both customers and power suppliers desire to maintain the power supply as a perfect 60$\mathrm{Hz}$ sine wave. Many loads, especially electronic equipment, are sensitive to the input waveform. Regulating bodies and standard-setting organizations establish limits for maximum allowable deterioration in harmonic content. Disturbances to the waveform can originate on the utility system (as a result of transformer excitation current or capacitor switching, for example) or on the customer's system (e.g., solid state power supplies and motor drives). Table 4 identifies some common types of power-quality disturbances. Because harmonics generated by one customer can adversely affect another customer, the utility seeks to ensure that the power delivered to each customer meets standards for waveform quality. The utility must eliminate harmonic sources on its system. It must also ensure that one customer does not propagate power-quality problems through the power system to other customers. In some ways, this service is the transmissionsystem complement to the generation service of stability enhancement.

Harmonics can be removed and power quality improved through the use of filters. Inductive filters placed in series with the line can block the flow of harmonics. Capacitive filters placed between line phases (delta) or between the line and ground (wye) can absorb harmonics. Different filters are used to absorb different frequencies of harmonics.

Because system impedance rises with frequency, harmonics generally do not travel long distances. Therefore, the problems they produce are localized, and filters designed to remove harmonics from the system must be located near the source of the harmonics.

The cost of filtering equipment required to clean up the harmonics produced by powersystem equipment necessary for system operation (static-var compensators, SMES, DC lines, DC$\mathrm{DC}$ connections, flexible-AC transmission systems, etc.) should be borne by all the users of the power system (or at least all of the users who benefit from the equipment producing the harmonics). The cost of filtering equipment that is necessary because a load is producing harmonics should be borne by that particular customer. A customer can avoid the cost of these latter filters by ensuring that it does not impose a harmonic burden on the system.

A third party could install filters to remove harmonics from the power system. For example, a customer in an industrial park that required filters for its own load could install larger filters to remove the harmonics produced by other loads within the industrial park. In this case, the customer should be paid for the harmonic-removal service.

In general, the cost of harmonic filters, when spread over the entire system, is quite small, but the costs for a specific installation can be large (millions of dollars). 
Table 4. Types of power-quality problems

\begin{tabular}{ll}
\hline Name & Explanation \\
\hline Surge & $\begin{array}{l}\text { Usually lasts less than } 0.001 \text { seconds, can jump to four times normal voltage, } \\
\text { and is often caused by lightning }\end{array}$ \\
Swell & $\begin{array}{l}\text { Usually lasts longer than } 0.03 \text { seconds, small voltage variations, and is often } \\
\text { caused by a large change in customer load or by the switching on or off of } \\
\text { utility equipment }\end{array}$ \\
Sag & $\begin{array}{l}\text { Usually lasts } 0.05 \text { to } 0.2 \text { seconds, with voltages up to } 20 \% \text { less than normal, } \\
\text { and is often caused by system overload }\end{array}$ \\
Notch & $\begin{array}{l}\text { Usually lasts less than } 0.03 \text { seconds, is characterized by a momentary loss of } \\
\text { power, and is often caused by starting loads or utility equipment failure }\end{array}$ \\
\hline
\end{tabular}
Source: adapted from Pacific Gas and Electric (1992). 


\section{COMPARISON WITH OTHER DEFINITIONS}

In this chapter, we compare the nomenclature and definitions developed in Chapters 3 and 4 with those used by several utilities. Specifically, we present the services suggested by Arizona Public Service (Beals 1994), Consumers Power (Lefere 1994), Detroit Edison (Musial 1994), Pacific Gas \& Electric (Metague 1994), and Southern California Edison (Nunnally 1995); see Table 5.

Arizona Public Service divided its list of "unbundled services" into the following classes: firm and nonfirm requirements (generation), firm and nonfirm transmission, area control, and standby services. Pacific Gas \& Electric assigned functions to ancillary services, other controlarea costs, other grid-related enforcement mechanisms, and unbundled merchant services. Southern California Edison included coordination, planning reserves, spinning reserves, and load following as generation-related ancillary services plus losses and voltage support as transmissionrelated ancillary services. Detroit Edison and Consumers Power, because they were required to file retail-wheeling tariffs with the Michigan Public Service Commission, provided the greatest detail on these services, their cost bases, and suggested tariff components. Detroit Edison classified services as administrative, transmission, or ancillary.

The New England Power Pool (1995) identified ten services that "must be provided by the control area," including: (1) tie-line/frequency regulation, (2) inadvertent-energy management, (3) time-error management, (4) interchange-schedule implementation, (5) administration of intercontrol-area emergency transactions, (6) online-capacity management, (7) operating-reserve margin, (8) planned-transmission-outage coordination, (9) planned-generation-outage coordination, and (10) transmission-system operation. NEPOOL identified 15 additional services that need not necessarily be provided by the system operator. The operating (nonplanning) functions in this list include: generation-unit commitment, online-generation dispatch, contract scheduling, provision of operating reserves, dispatchable-load management, transmission-facility scheduling, voltage control, and system restoration after loss of power. Because the NEPOOL analysis focused on the "central dispatch and the services which central dispatch provides," mapping the NEPOOL functions onto the services described above, which focus more on the services that customers receive, is difficult.

Because the utilities had different purposes in mind when they identified these various services, their coverage differed. For example, only Arizona Public Service and Southern California explicitly identified the basic generation capacity services that we discussed in Chapter 2. The other utilities presumably did not include these services because their focus was 


\section{Table 5. Comparison of different names for generation and transmission services}

\begin{tabular}{|c|c|c|c|c|c|}
\hline $\mathrm{ORNL}^{\mathrm{a}}$ & $\begin{array}{l}\text { Arizona Public } \\
\text { Service }\end{array}$ & Consumers Power ${ }^{b}$ & Detroit Edison $^{c}$ & $\begin{array}{l}\text { Pacific Gas \& } \\
\text { Electric }^{d}\end{array}$ & $\begin{array}{l}\text { Southern California } \\
\text { Edison }\end{array}$ \\
\hline Generation capacity & Resource capacity & & & & Planning reserves \\
\hline Energy supply & Resource energy & & & & \\
\hline Power delivery & Firm transmission & $\begin{array}{l}\text { Capacity-reservation } \\
\text { and transmission } \\
\text { services }\end{array}$ & $\begin{array}{l}\text { Capacity reservation, } \\
\text { transmission service, } \\
\text { and generation } \\
\text { support }\end{array}$ & $\begin{array}{l}\text { Basic transmission } \\
\text { service }\end{array}$ & Planning reserves \\
\hline $\begin{array}{l}\text { Unit Commitment } \\
\text { Economic dispatch }\end{array}$ & $\begin{array}{l}\text { Scheduling, } \\
\text { dispatching, unit } \\
\text { commitment }\end{array}$ & $\begin{array}{l}\text { Schedule change and } \\
\text { customer charges }\end{array}$ & $\begin{array}{l}\text { System control and } \\
\text { load dispatch }\end{array}$ & $\begin{array}{l}\text { Scheduling and } \\
\text { billing }\end{array}$ & Coordination \\
\hline \multirow{5}{*}{$\begin{array}{l}\text { Reserve generating } \\
\text { capacity } \\
\text { - Load-following } \\
\text { spinning } \\
\text { - Reliability spinning } \\
\text { - Unscheduled energy } \\
\text { - Supplemental } \\
\text { operating } \\
\text { - Stability enhancement } \\
\text { - Local-area security } \\
\text { - Nonoperating reserves }\end{array}$} & $\begin{array}{l}\text { Reserves: spinning, } \\
\text { ready, available }\end{array}$ & & Standby reservation & Standby generation & \\
\hline & $\begin{array}{l}\text { Area-control } \\
\text { options: regulation, }\end{array}$ & & & $\begin{array}{l}\text { Regulation } \\
\text { Spinning and }\end{array}$ & \\
\hline & $\begin{array}{l}\text { frequency support, } \\
\text { system control }\end{array}$ & & $\begin{array}{l}\text { Spinning reserve } \\
\text { Unauthorized use } \\
\text { Supplemental reserve }\end{array}$ & $\begin{array}{l}\text { nonspinning reserve } \\
\text { Unforecasted power } \\
\text { Emergency power }\end{array}$ & Spinning reserves \\
\hline & System constraints & System support & Redispatch & Uneconomic dispatch & \\
\hline & Planning reserves & & & & \\
\hline $\begin{array}{l}\text { Transmission } \\
\text { monitoring and control }\end{array}$ & $\begin{array}{l}\text { Flow control } \\
\text { devices }\end{array}$ & & & & \\
\hline $\begin{array}{l}\text { Real-power-loss } \\
\text { replacement }\end{array}$ & Losses & Line-loss replacement & $\begin{array}{l}\text { Loss capacity and } \\
\text { energy }\end{array}$ & Losses & Losses \\
\hline $\begin{array}{l}\text { Reactive-power } \\
\text { management and } \\
\text { voltage regulation }\end{array}$ & VAR support & $\begin{array}{l}\text { Part of system } \\
\text { support }\end{array}$ & $\begin{array}{l}\text { Voltage control and } \\
\text { reactive support }\end{array}$ & $\begin{array}{l}\text { Voltage support, } \\
\text { Reactive support } \\
\text { noncompliance }\end{array}$ & Voltage support \\
\hline
\end{tabular}




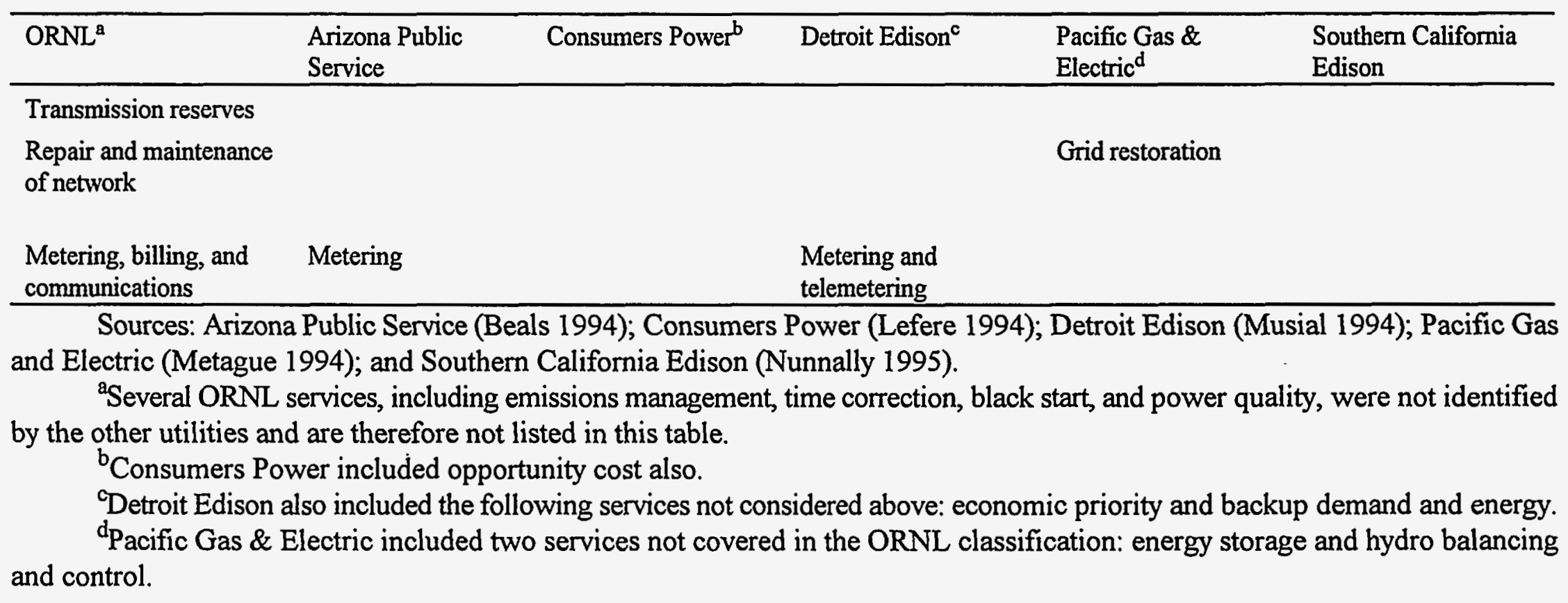


on wholesale or retail-wheeling services, in which customers would provide their own generation. All five utilities, however, included basic transmission services (what we call power delivery).

The utilities differed in the services they included under what we call unit commitment and economic dispatch. Arizona Public Service included unit scheduling, commitment, and dispatch, but the other utilities included only the scheduling services. That is, the other utilities apparently consider unit commitment and scheduling a service to be provided by the customer or its supplier, not by the system operator.

The names for and purposes of extra generating capacity differed among the sets of definitions. We found it difficult, based on the limited information from these utilities, to determine whether the services covered the same functions as those discussed in Chapter 3.

All five utilities identified transmission-system losses and VAR support as services, but most did not explicitly identify transmission monitoring and control, transmission reserves, and repair and maintenance of the transmission system.

These similarities and differences among the names and services identified by different organizations emphasize the importance of the current ORNL project. Absent clear names and definitions for the various services provided by the integrated electric-power system, it will be difficult to design, cost, and price these services. The Electric Power Research Institute is conducting a major project on transmission-services costing, which will contribute to the development and use of standard definitions (Wakefield, Limmer, and Graves 1994). 


\section{CONCLUSIONS}

We developed an initial list of services that are provided by electric-power systems. We defined each service and indicated whether it was mandatory or optional for end-use customers and whether or not customers could supply the service themselves or obtain that service from an entity other than the system operator (Table 6). We expect that the names and definitions of these services will change with time as both markets and technologies evolve. For example, some services that we now consider mandatory and under the control of the system operator may, in a few years, be optional and obtainable from various sources.

Comparing the NERC Operating Manual with a recent filing before FERC (Coalition for a Competitive Electric Market 1995) illustrates well these possible changes. The NERC standards, based on electrical-engineering principles, are detailed and specific. The Coalition's petition, based on marketing principles, calls for complete unbundling of transmission services and prices.

This report is the first step in a larger project. Future activities in this project include onsite visits with utilities and power pools that operate control areas as well as with users of such systems (especially power brokers and marketers). Using the nomenclature and definitions developed here, we will use these meetings to clarify the details of each service and to identify its underlying cost basis. We will see if common methods can be developed to estimate the costs and establish prices for different services. In a later report, we plan to publish a refined version of Table 6, which will provide greater clarity and specificity concerning these ancillary services. In particular, we plan to assess each service to see whether its costs can be identified and separated from the costs of other services and whether the cost of the service is high enough to warrant the transaction costs associated with its measurement and billing.

Three leading economists recently addressed the role of unbundling in a competitive electricity industry (Baumol, Joskow, and Kahn 1994):

If we can successfully unbundle the transmission functions, identifying all of the monopoly grid services now being provided, assigning clear property rights to the facilities that supply them, measuring what is supplied from whom to whom and properly pricing each, we can permit more thoroughgoing competition in generation without concern about its causing inefficiencies. If we are unable to do so, it is entirely possible that the efficiency benefits flowing from competitive generation could be entirely dissipated or indeed more than entirely offset by the 
Table 6. Preliminary assessment of ancillary services

\begin{tabular}{|c|c|c|c|c|}
\hline Service & $\begin{array}{l}\text { Required or } \\
\text { optional }\end{array}$ & $\begin{array}{c}\text { Must be } \\
\text { obtained from } \\
\text { system } \\
\text { operator? }^{\mathrm{a}}\end{array}$ & $\begin{array}{l}\text { Relative } \\
\text { cost }\end{array}$ & $\begin{array}{l}\text { Control } \\
\text { or } \\
\text { metered? }\end{array}$ \\
\hline Generation capacity & Optional $^{b}$ & No & High & $\mathrm{M}$ \\
\hline Energy supply & Optional $^{b}$ & No & High & M \\
\hline Power delivery & Optional & Yes & Medium & $\mathrm{C}$ \\
\hline Unit Commitment & Optional & No & Low & \\
\hline Economic dispatch & Optional & Yes & Low & \\
\hline $\begin{array}{l}\text { Reserve generating capacity } \\
\text { - Load-following spinning } \\
\text { - Reliability spinning } \\
\text { - Unscheduled energy } \\
\text { - Supplemental operating } \\
\text { - Time correction } \\
\text { - Stability enhancement } \\
\text { - Local-area security } \\
\text { - Nonoperating reserve }\end{array}$ & $\begin{array}{c}\text { Required } \\
\text { Required }^{\mathrm{c}} \\
\text { Required } \\
\text { Optional } \\
\text { Required } \\
\text { Required } \\
\text { Required } \\
\text { Optional }\end{array}$ & $\begin{array}{l}\text { No } \\
\text { Yes } \\
\text { Yes } \\
\text { Yes } \\
\text { Yes } \\
\text { Yes } \\
\text { Yes } \\
\text { No }\end{array}$ & $\begin{array}{l}\text { Medium } \\
\text { Medium } \\
\text { Low } \\
\text { Medium } \\
\text { Low } \\
\text { Medium } \\
\text { Medium } \\
\text { Medium }\end{array}$ & $\begin{array}{l}\mathrm{M} \\
\mathrm{C} \\
\mathrm{M} \\
\mathrm{C}\end{array}$ \\
\hline Black start & Required & Yes & Low & \\
\hline $\begin{array}{l}\text { Transmission monitoring and } \\
\text { control }\end{array}$ & Required & Yes & Low & \\
\hline Real-power-loss replacement & Required & Yes & Medium & M \\
\hline $\begin{array}{l}\text { System reactive-power } \\
\text { management and voltage } \\
\text { regulation }\end{array}$ & Required & Yes & Medium & M \\
\hline $\begin{array}{l}\text { Local reactive-power } \\
\text { management and voltage } \\
\text { regulation }\end{array}$ & Required & No & Medium & $\mathrm{C}$ \\
\hline Transmission reserves & Required $^{c}$ & Yes & Low & $\mathrm{C}$ \\
\hline $\begin{array}{l}\text { Repair and maintenance of } \\
\text { network }\end{array}$ & Required & Yes & Low & \\
\hline $\begin{array}{l}\text { Metering, billing, and } \\
\text { communications }\end{array}$ & Required & Yes & Low & \\
\hline Power quality & Optional & No & Medium & $\mathrm{M}$ \\
\hline
\end{tabular}


deteriorated coordination between that sector and transmission. Insuring against these possible consequences is an extremely important responsibility of policy makers, and it can not be sensibly postponed. This should be a key topic for policy makers as they contemplate industry restructuring, the role of competition, and how the industry will be organized to promote efficient competition.

Customer choice is the essence of competition. Therefore, customers must know what the different services are and from whom they can obtain them. Electricity-service providers need to understand much better their cost structures to determine which services to offer and how to price them. This report is a step in those directions.

\section{ACKNOWLEDGMENTS}

We thank Darrell Anderson, Douglas Fisher, Edward Hillsman, John Hughes, Val Jensen, Robert Johnson, Edward Kahn, Jack Lawler, Lou Leffler, David Meyer, Ronald Nunnally, Bernard Pasternack, Phil Overholt, Paul Rodzianko, Antonio Sammut, Ali Vojdani, Keith Van Ausdal, and Robert Wolff for their very helpful comments on a draft of this report. We thank Fred O'Hara for editing the report and thank Ethel Schorn for shepherding the report through the ORNL clearance and printing processes. 


\section{REFERENCES}

W. J. Baumol, P. L. Joskow, and A. E. Kahn 1994, The Challenge for Federal and State Regulators: Transition from Regulation to Efficient Competition in Electric Power, prepared for the Edison Electric Institute, Washington, DC, December.

D. F. Beals 1994, personal communication, Power Contracts Development and Administration, Arizona Public Service Company, Phoenix, AZ, November.

Bonneville Power Administration 1994, "Loop Flow Problem Solved," Journal, Portland, OR, January.

California Public Utilities Commission 1994, Order Instituting Rulemaking on the Commission's Proposed Policies Governing Restructuring California's Electric Services Industry and Reforming Regulation, R.94-04-31, San Francisco, CA, April 20.

Coalition for a Competitive Electric Market 1995, Petition of Coalition for a Competitive Electric Market for a Rulemaking on Comparability, before the Federal Energy Regulatory Commission, Washington, DC, February 16.

L. Cullen, G. Mathis, D. Ray, and R. Stevenson 1994, Policy Options for Competition in Wisconsin's Electric Power Industry, Wisconsin Public Utility Institute, University of Wisconsin, Madison, WI, September.

Electric Light \& Power 1995, "Power Outage Hits West Coast," 73(2), 1, February.

Energy Information Administration 1993, Financial Statistics of Major U.S. Investor-Owned Electric Utilities 1992, DOE/EIA-0437(92)/1, U.S. Department of Energy, Washington, DC, December.

B. F. Hobbs 1994, personal communication, Case Western Reserve University, Cleveland, OH, December.

W. W. Hogan 1992, "Contract Networks for Electric Power Transmission," Journal of Regulatory Economics, 211-242.

W. W. Hogan 1993, A Competitive Electricity Market Model, Draft, Kennedy School of Government, Harvard University, Cambridge, MA, October. 
E. Kahn 1995, personal communication, Energy and Environment Division, Lawrence Berkeley Laboratory, Berkeley, CA, February 28.

R. P. Lefere, Jr. 1994, "Testimony," Cases No. U-10143 and U-10176 Before the Michigan Public Service Commission, Consumers Power, Jackson, MI, August.

J. Liodra and F. Depenbrock 1994, "How Pumped Storage can Boost Network Security," Electrical World, March.

J. Matusz 1994, Real Losses, Detroit Edison, Detroit, MI, May.

S. J. Metague 1994, personal communication, Transmission Contracts Department, Pacific Gas and Electric Company, San Francisco, CA, December .

Michigan Public Service Commission 1994, Opinion and Interim Order Remanding to the Administrative Law Judge for Further Proceedings, Cases No. U-10143 and U-10176, Lansing, MI, April 11.

J. J. Musial 1994, "Qualifications and Direct Testimony," Cases No. U-10143 and U-10176 Before the Michigan Public Service Commission, Detroit Edison, Detroit, MI, August 24.

New England Power Pool 1995, Review of NEPOOL Structure: Phase One Report, Holyoke, MA, January.

North American Electric Reliability Council 1994, NERC Operating Manual, Princeton, NJ.

R. D. Nunnally 1995, personal communication, System Planning Department, Southern California Edison, Rosemead, CA, March 1.

S. Oren, P. Spiller, P. Varaiya, and F. Wu 1994, Nodal Prices and Transmission Rights: A Critical Appraisal, PWP-25, University of California, Energy Institute, Berkeley, CA, December.

Pacific Gas and Electric Company 1992, Resource, An Encyclopedia of Energy Utility Terms, 2nd edition, San Francisco, CA.

A. Sammut 1994, "Detroit Edison's Service Pricing Initiative, Ancillary/Unbundled Electric Service," Detroit Edison, Detroit, MI. April.

U.S. House of Representatives 1994, "Electricity Issues that Have Followed Enactment of the Energy Policy Act of 1992," Hearings, Committee on Energy and Commerce, Subcommittee on Energy and Power, Washington, DC, July 13, 14, and 21. 
U.S. Federal Energy Regulatory Commission 1992, FERC Form No. 1: Annual Report of Major Electric Utilities, Licensees and Others, Washington, DC.

U.S. Federal Energy Regulatory Commission 1994a, Inquiry Concerning the Commission's Pricing Policy for Transmission Services Provided by Public Utilities Under the Federal Power Act, Policy Statement, Docket No. RM93-19-000, Washington, DC, October 26.

U.S. Federal Energy Regulatory Commission 1994b, Notice of Inquiry, Alternative Power Pooling Institutions Under the Federal Power Act, Docket No. RM94-20-000, Washington, DC, October 26.

R. A. Wakefield, H. D. Limmer, and J. S. Graves 1994, Transmission Services Costing Framework, Volume 1: Interim Report on Technical and Economic Fundamentals, EPRI TR104226, CSA Energy Consultants and Putnam, Hayes \& Bartlett, Inc., prepared for the Electric Power Research Institute, Palo Alto, CA, August. 


\section{CONTROL OF GENERATION}

Interconnected utilities use a two-level system of automatic controls to coordinate the operation of thousands of generators spread across North America and grouped into about 150 control areas. [Much of the material in this appendix is from NERC (1994).] Because electric power cannot be practically stored in large quantities, it is necessary to continuously match the generation to the load. Local control is exercised by governors on individual machines. Automatic generation control (AGC) coordinates the actions of the individual machines to control each area and the interactions among areas. Both the individual generator governors and the AGC system are used to maintain the balance between generation and load. The control actions are the same for a loss of generation as for an increase in load, although load changes will generally be smaller and more frequent than unexpected generation changes.

\section{GOVERNOR CONTROL}

Because the vast majority of generators and most heavy loads rotate, system electrical frequency and load are strongly coupled. Most generators are equipped with governors that regulate the unit output in an attempt to maintain constant frequency $(60 \mathrm{~Hz})$. The governors are given a slight "droop" ( $\Delta \mathrm{MW} / \Delta \mathrm{Hz}$, typically $5 \%)$ that allows the power output to drop as the frequency increases. This droop allows coordination among many generators.

For an isolated generator with its load, if the load decreases but the energy (typically, steam) being supplied to the prime mover does not decrease, the generator will naturally accelerate. The generator's governor will detect this slight increase in frequency (speed), and will call for reduced output from the machine (because of the droop) by reducing the energy supply to the turbine. The system behaves analogously when loads increase. The net effect is that the frequency will change slightly but the electric generation will match the load. This response is continuous and very rapid (within milliseconds to seconds, depending on the generator).

\section{AUTOMATIC GENERATION CONTROL}

Governor action alone is not sufficient in an interconnected system, however, because all of the generators on the system would respond to every change in load whether they were responsible for meeting that load or not. Utilities increase the accuracy of control and assure that each utility provides for its own load by defining subdivisions of the grid called control areas 
across whose boundaries power flows are measured and controlled. Any deviation of net flow into or out of a control area from the net scheduled flow reflects an imbalance between load and generation. This imbalance is called area control error (ACE) and is measured in MW. NERC guidelines require that the flows be measured and that $\mathrm{ACE}$ be computed at least once every four seconds. Utilities dedicate a portion of their online generation to ensure frequent zero crossings of $\mathrm{ACE}$ and to control the interchange between control areas. They do this without operator action using AGC. AGC monitors the ACE and adjusts the MW-output set point of the generator governors to minimize ACE.

For example, if load increases (but the generation does not), then all of the generators on the system will begin to decelerate because more energy is being removed from the system than is being put into it. As frequency drops (slightly), all the governors automatically call for increased output from their generators. Some of the responding generators will be outside the local control area. AGC notes that more power is coming into the area than was scheduled (ACE). To eliminate this ACE, the AGC will increase the set points of each of the generators under AGC within the control area so they will be producing more power at the $60-\mathrm{Hz}$ set point. AGC does not adjust the droop, it simply raises the MW output being called for at the $60-\mathrm{Hz}$ set point. AGC control action is slower than governor action but is generally effective within two to three minutes in driving ACE to zero. The system is once more in balance, with area interchanges at scheduled levels and generators running at $60 \mathrm{~Hz}$.

These activities ensure that load and generation are matched in each control area. Frequency can vary slightly however. To reduce frequency variations, the calculation of ACE also includes a frequency-bias term. Each control area calculates a frequency bias (expressed in $\mathrm{MW} / 0.1 \mathrm{~Hz}$ ) that is as close as practical to the control area's actual frequency-response characteristic at peak load. The frequency-response characteristic is the combined effect of governor action and the change in load in a control area associated with a frequency change. The area frequency-response characteristic can be determined by observing the net change in tie-line loading when there is a sudden change in frequency. The frequency bias is then added into the ACE calculation. The frequency bias for. TVA for 1994, for example, was $236 \mathrm{MW} / 0.1 \mathrm{~Hz}$. If the frequency were to drop to $59.9 \mathrm{~Hz}$, then the ACE calculation for TVA would call for TVA to generate $236 \mathrm{MW}$ more than if the frequency were $60.0 \mathrm{~Hz}$. Since each control area participates in this control, the frequency is regulated quite close to $60.0 \mathrm{~Hz}$ (usually within $\pm 0.01 \mathrm{~Hz}$ ).

An additional refinement is made to AGC. Frequency and tie-line flow deviations are sensitive to fluctuations in generation or load throughout the system. By watching both the tie-line flows and the frequency deviation, it is possible to determine if the generation/load imbalance is inside or outside the control area (Table A-1). For example, if the frequency is rising (generation exceeding load) and the tie-line flows are greater than scheduled (more power is leaving the area than is scheduled), the imbalance is inside the control area. (The control area has more generation than is required, and it is exporting the excess to the system.) 
Table A-1. Source of generation/load imbalance as a function of frequency and tie line flows

\begin{tabular}{lll}
\hline Direction of excess tie-line flow & \multicolumn{2}{c}{ Frequency } \\
\cline { 2 - 3 } & \multicolumn{1}{c}{$>60 \mathrm{~Hz}$} & $<60 \mathrm{~Hz}$ \\
\hline Out & Internal load loss & External generation loss \\
In & External load loss & Internal generation loss \\
\hline
\end{tabular}

For imbalances inside the control area, the AGC operates and adjusts generation to correct the imbalance. For imbalances outside the control area, however, AGC action is suppressed, and the AGC of the control area where the imbalance exists is expected to correct the problem. Governors on all machines respond independent of the location of the imbalance. This response provides support to an area with a sudden loss of generation by allowing all machine governors to respond by raising generation without having the AGC in neighboring areas attempting to reduce flows into the affected area. The AGC in the affected area will raise generation as much as possible to compensate for the loss. Operators may negotiate changes to intertie schedules if further generation is needed.

Utilities generally spread AGC over as many generators as possible because there are physical limits to the rate at which each unit can respond to AGC commands. Having more generators under AGC control allows for faster overall response. Any generating unit equipped with a governor and $\mathrm{AGC}$ can provide spinning reserve. 


\section{REACTIVE POWER}

To understand reactive power and the relationship between power factor and voltage support, it is necessary to understand alternating current (AC). The voltage and current produced by a generator oscillate 60 times a second with the shape of a sine wave. The sine wave is the natural motion of a rotating circle and is produced because generators rotate at constant speed. Both the voltage and the current vary as sine waves.

Power is the product of voltage $(\mathrm{V})$ and current $(\mathrm{I}): \mathrm{P}=\mathrm{V} \times \mathrm{I}$. Figure $\mathrm{B}-1$ shows that this product is always positive if the voltage and current oscillate together, even though both the voltage and the current are negative half the time. The power pulsates for a single phase (one set of voltage and current). Power systems use three phases offset by 120 degrees from each other (delayed by $1 / 3$ of a cycle) so that the total power from all three phases is constant.

If the current wave is delayed slightly from the voltage wave, the two are no longer in phase, and the current is said to lag the voltage. The resulting power is sometimes positive (the generator is delivering power to the load) and sometimes negative (the generator is taking power from the load). In this case, there is a net transfer of energy (power flow) from the generator to the load but there is also an oscillation of energy 120 times a second between the generator and the load. If the current lags the voltage by 90 degrees, the power oscillates but there is no net energy transfer from the generator to the load (Fig. B-2).

\section{INDUCTORS AND CAPACITORS}

Power oscillations between the generator and the load occur whenever the load has the ability to instantaneously store energy. Both inductors and capacitors store energy. Inductors store energy in a magnetic field, which results from the current flowing in the wire of an inductor. Capacitors store energy in an electrostatic field, which results from the voltage difference between the plates of a capacitor.

This storage of energy and oscillation of power can be explained by considering an inductor connected to an $\mathrm{AC}$ generator. When the generator voltage is at its maximum, current begins to build in the inductor (point A on Figure B-3), storing energy in the inductor's magnetic field. When the voltage reverses (point $B$ ), the current is still flowing in the inductor in the positive direction because energy has built up in the inductor's magnetic field. The energy flows out of the inductor and into the generator because of the negative generator voltage and the positive inductor current. As the magnetic field in the inductor collapses, energy leaves the inductor and the current drops. Once the energy, magnetic field, and current drop to zero (point 
C), the current and magnetic field start building in the opposite direction, driven by the generator's negative voltage. Power flows from the generator to the inductor again because both the voltage and the current are negative, storing energy in the inductor. This lasts only as long as the voltage remains negative. When the generator reverses voltage again (point $D$ ), the positive generator voltage and negative inductor current send power from the inductor to the generator, reducing the stored energy in the inductor. At point $\mathrm{E}$, the generator voltage has again reached a maximum and the process repeats itself.

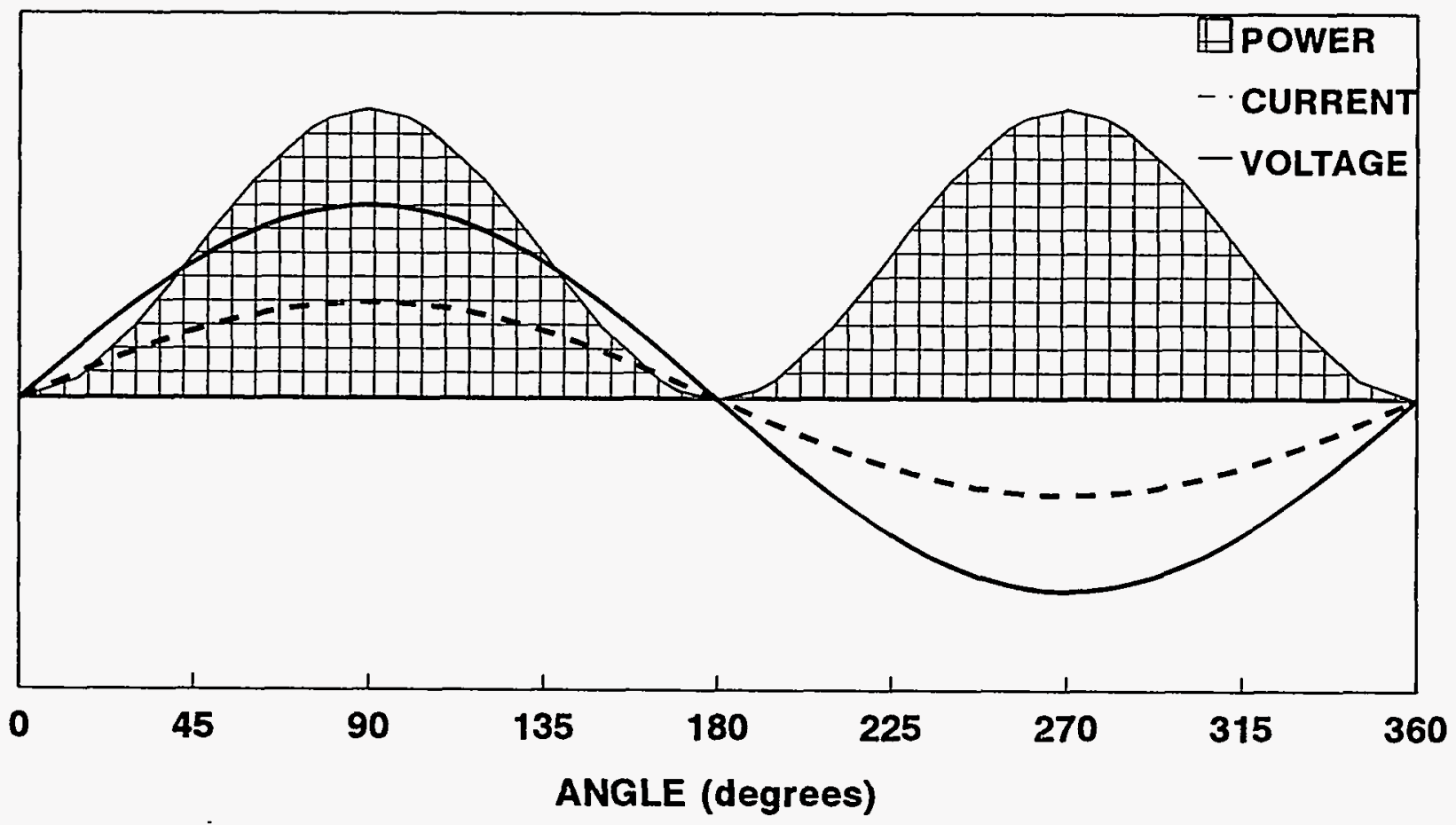

Fig. B-1. The relationship between current and voltage to produce power.

Capacitors behave the same way except that the current leads the voltage by 90 degrees and the energy is stored in the electrostatic field (depending on voltage). The power flows between the $\mathrm{AC}$ generator and the capacitor are opposite from the power flows between the generator and the inductor. That is, when power is flowing from the generator to the inductor (between points A and B in Fig. B-3), power is flowing from the capacitor to the generator. When the energy stored in the inductor is at its lowest (points A, C, and E in Fig. B-3), the energy stored in the capacitor is at its highest.

None of this would be important except that nearly all power-system components have capacitance and/or inductance associated with them. In fact, inductance is the dominant characteristic of most power-system components (e.g., generators, overhead lines, transformers, and motors). Underground cables and, to a lesser extent, overhead lines have significant capacitance, as well. Consequently, these oscillations occur all the time. 


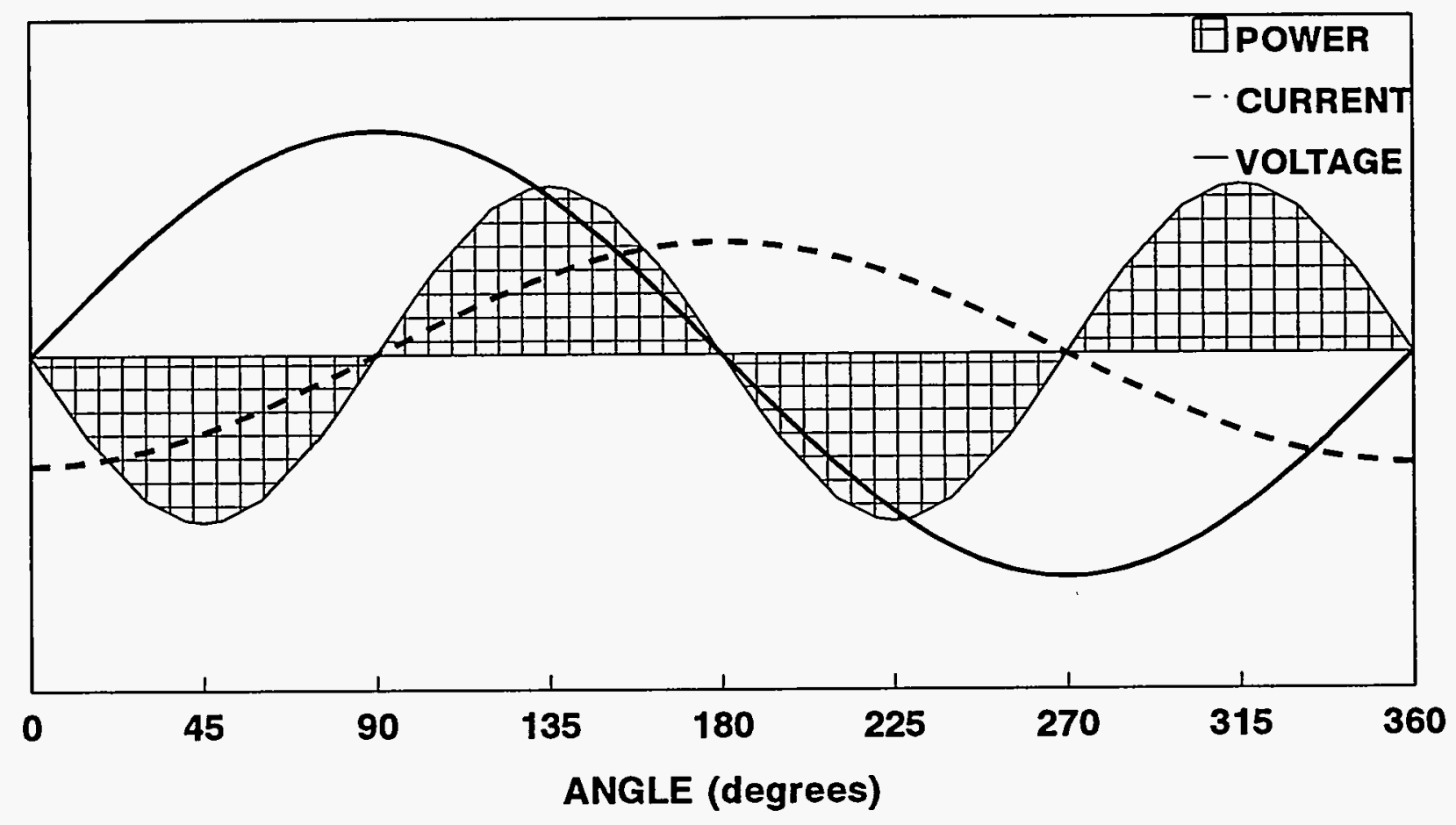

Fig. B-2. Relationship between lagging current and voltage and resultant power output. With current lagging voltage by 90 degrees, there is no net power transfer.

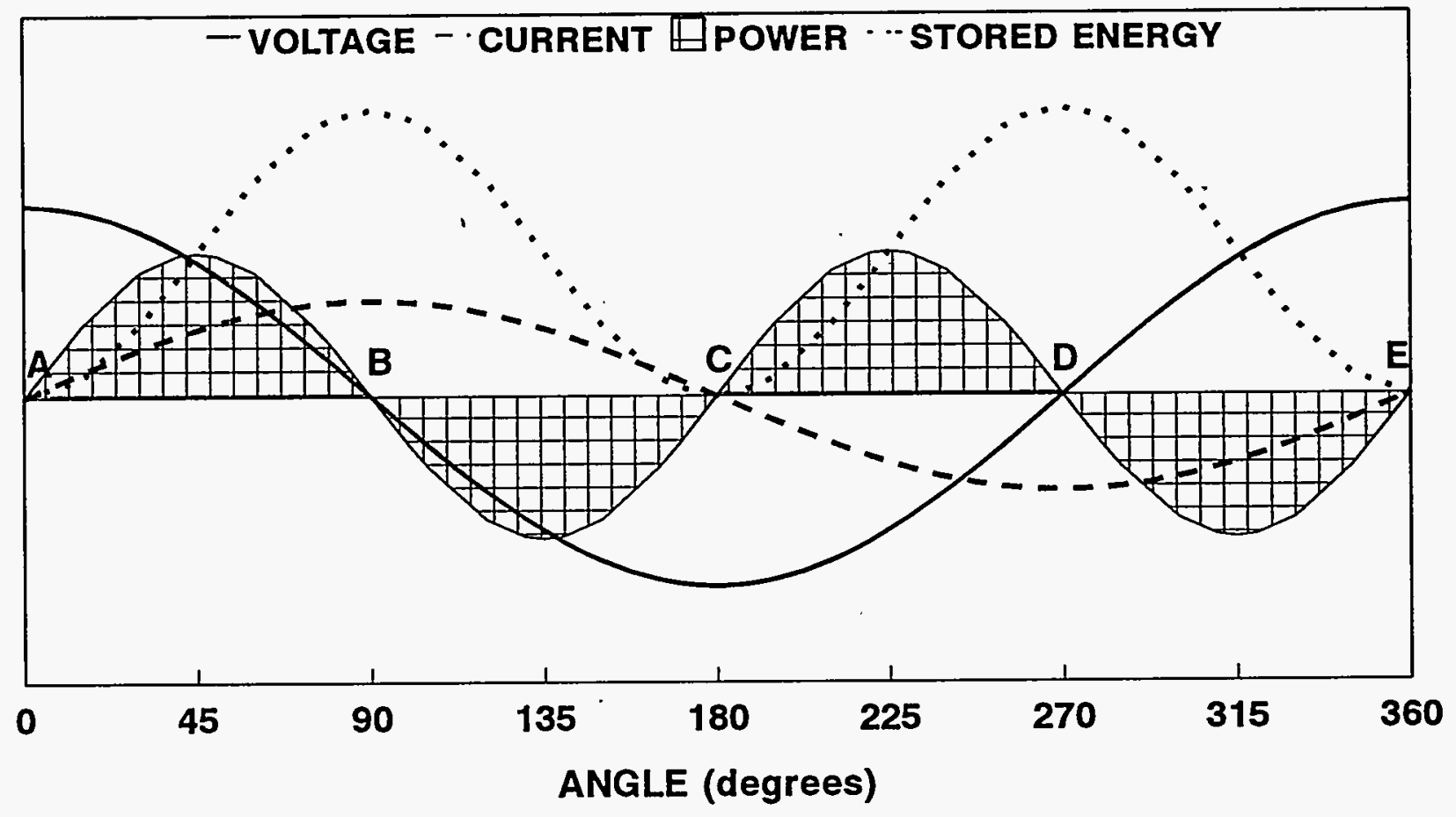

Fig. B-3. Power transfer and energy oscillations in the presence of an inductor. 


\section{POWER FACTOR}

Current associated with transferring energy back and forth between the $\mathrm{AC}$ generator and the inductor or capacitor does not deliver useful energy to the load. The concept of power factor was developed to express how much of the total current supports the transfer of useful energy to the load (real power) and how much supports oscillations (reactive power). Because reactive power results from current that is out of phase with voltage by 90 degrees (either lagging because of inductance or leading because of capacitance) and real power results from current that is in phase with voltage, the two add geometrically to form apparent power. Power factor is defined as the ratio of real power to apparent power. Real power is measured in watts (W), reactive power is measured in volt-amps reactive (VAR), and apparent power is measured in volt amps (VA).

Transmission-system components, such as transmission lines and transformers, have to carry the total current or the apparent power. Load losses (e.g., the losses associated with the resistance of transmission lines) also result from the total current. The lower the power factor and the greater the reactive load, the higher the losses.

Most transmission-system equipment is limited in the amount of current it can carry because high currents passing through the small resistance of the equipment generate heat that must be removed. ${ }^{*}$ So poor power factor lowers the capacity of the transmission system to move useful energy to the load by consuming some of the limited current-carrying capacity with reactive current.

Because inductive current lags voltage and capacitive current leads voltage, the two can be used to cancel each other. If a load is inductive (as nearly all loads are because of motors, fluorescent light ballasts, transformers, etc.), it can be compensated for with capacitors so the total load presented to the power system has a power factor of $100 \%$ (or any other desired value). Most industrial and many commercial power contracts require the customer to maintain a power factor above some minimum level (often $95 \%$ ). Customers can install capacitors to adjust their power factor if it is below this limit.

\section{VOLTAGE DROP}

Voltage drop results from the interaction of the current with the impedance (resistance, capacitance, and inductance) of the transmission line or transformer. Current (I) passing through

For overhead transmission lines, the current creates heat, which expands and weakens the conductor. The thermal limit of the line is reached when the line either sags too low to be safe or weakens and pulls apart. For transformers, the current heats transformer mass and eventually damages the insulation. In both cases, the thermal time constants of the equipment, the amount of the overload, and the ambient temperature determine how long the overload can be tolerated. 
a resistor $(R)$ produces voltage drop $(\Delta V): \Delta V=I \times R$. If the load is real (100\% power factor), the voltage at the load plus the resistive voltage drop in the transmission lines equals the generator voltage. If the transmission-line impedance is inductive rather than resistive, the voltage drop across the inductor is rotated 90 degrees from the load current. The line voltage drop is the same magnitude as in the resistive case, but because it is not aligned with the supply voltage, the resulting load voltage is higher than in the resistive case (although it now lags the supply voltage). If the load current is inductive itself and therefore lags the supply voltage by 90 degrees, the resulting voltage drop in the inductive line is once again aligned with but opposite to the supply voltage. So inductive loads supplied through inductive lines have higher voltage drops than do real loads supplied through inductive lines (Fig. B-4).
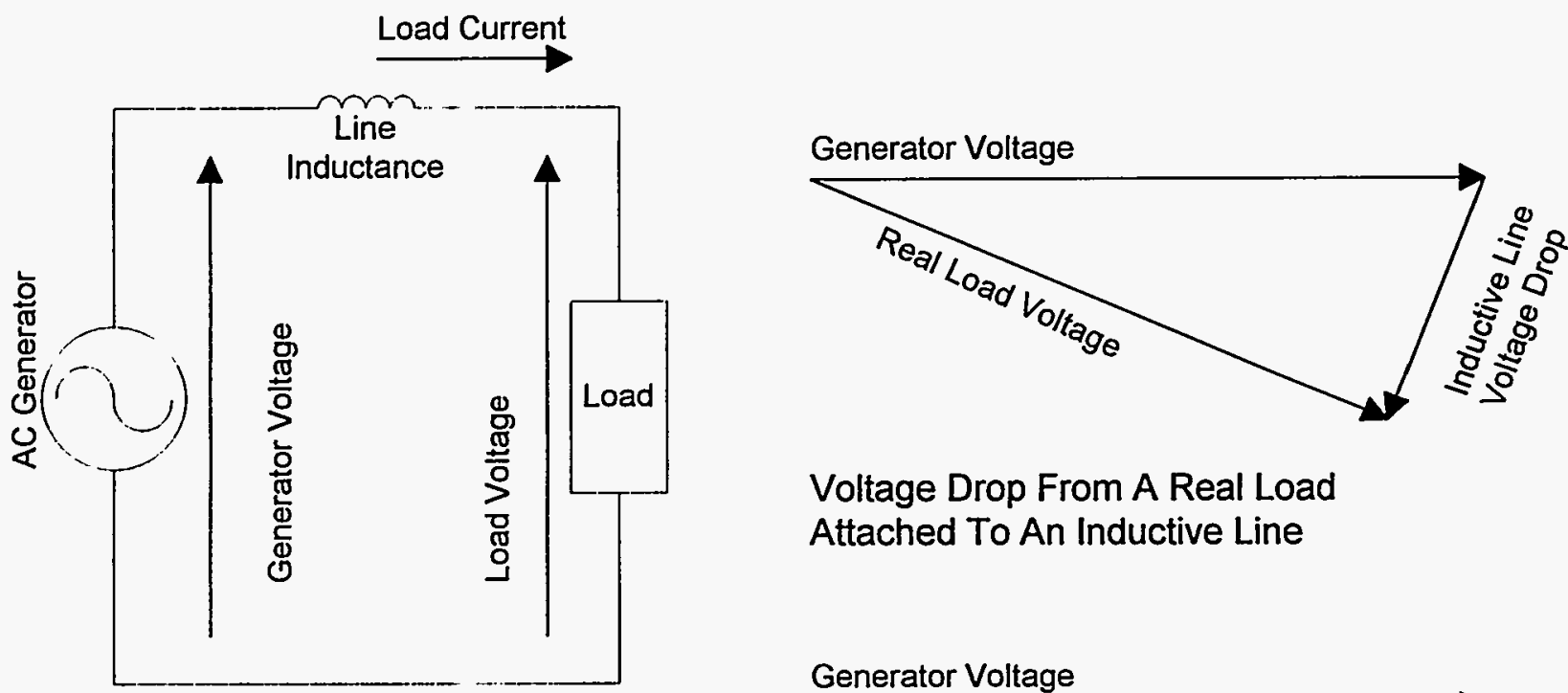

Voltage Drop From A Real Load

Attached To An Inductive Line

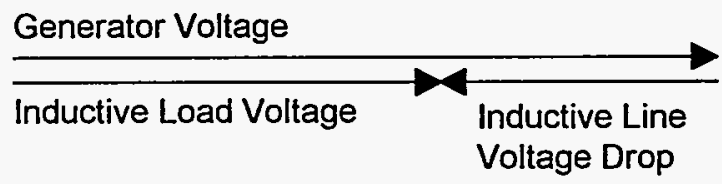

Voltage Drop From An Inductive Load

Attached To An Inductive Line

Fig. B-4. Voltage drop caused by a real load and an inductive load supplied through an inductive line.

Overhead lines and transformers have series inductive reactances that are on the order of 10 times their series real impedances (i.e., the inductance is 10 times the resistance). This difference is because resistance is related to the properties of the conductor and the amount of it that is used, while the inductance and capacitance are related to the geometry of how the equipment is constructed. Conductors are made from copper or aluminum because these materials have low resistance and not from steel (except to carry weight) because it has higher resistance. 
Resistance can be further reduced by using a bigger conductor. For an overhead transmission line, the inductance depends on the geometry of the conductors. The dominant factor is the spacing between the conductors, with higher inductance resulting from greater spacing. Large spacing is required, however, to insulate high-voltage conductors from each other. Because of this spacing, the reactive load (lower power factor) interacts with the higher inductive impedance to produce most of the voltage drop seen throughout the power system.

\section{REACTIVE COMPENSATION}

The fact that loads and transmission-system components have inductance, capacitance, and resistance leads both to a reduction in transmission-system capacity and to increased voltage drops. As alluded to above, capacitors can be used to compensate for the inductive demands of loads and transmission-system components. (Inductors can also be used to compensate when excessive capacitance is present on the system.) Compensating for the reactive demands of a load with capacitors increases the power factor, reduces the voltage drop, restores the transmission capacity, and reduces the need for generators to supply reactive current. 
INTERNAL DISTRIBUTION

1. D. Bauer

2. L. Baxter

3. V. D. Baxter

4. L. Berry

5. D. S. Bjornstad

6. R. Braid

7. M. A. Brown

8. F. C. Chen

9. J. Christian

10. G. Courville

11. T. R. Curlee

12. P. D. Fairchild

13. S. Hadley

14. L. J. Hill

15. E. Hillsman

16. E. Hirst

17. P. J. Hughes

18. B. Kirby

19. R. Lee
20. P. Leiby

21. J. M. MacDonald

22. V. C. Mei

23. D. E. Reichle

24. D. T. Rizy

25. A. C. Schaffhauser

26. M. Schweitzer

27. R. B. Shelton

28. J. Tomlinson

29. B. E. Tonn

30. J. Van Dyke

31. J. Vancoevering

32. J. M. Veigel (ORAU)

33. T. J. Wilbanks

34. ORNL Patent Office

35. Central Research office

36. Document Reference Section

37. Laboratory Records (RC)

38-40. Laboratory Records Dept.

\section{EXTERNAL DISTRIBUTION}

41. Dr. Thomas E. Drabek, Professor, Department of Sociology, University of Denver, Denver, CO 80208-0209

42. Dr. Stephen G. Hildebrand, Director, Environmental Sciences Division, Oak Ridge National Laboratory, Post Office Box 2008, Oak Ridge, TN 37831-6037

43. Mr. George F. Sowers, P. E., Senior Vice President, Law Companies Group, Inc., 114 Townpark Drive, Suite 250, Kennesaw, GA 30144-5599

44. Dr. C. Michael Walton, Ernest H. Cockrell Centennial Chair in Engineering and Chairman, Department of Civil Engineering, University of Texas at Austin, Austin, TX 78712-1076

45.-47. OSTI, U. S. Department of Energy, P. O. Box 62, Oak Ridge, TN 37831

48. Office of Assistant Manager for Energy Research and Development, DOE/ORO, P. O. Box 2001, Oak Ridge, TN 37831-8600

49.-750. External Energy and Global Change Analysis Section distribution mailing list and extra copies to E.M. Schorn, $4500 \mathrm{~N}, \mathrm{H}-19 \mathrm{~A}$ 